\title{
Full-scale collapse testing of a steel stiffened plate structure under axial-compressive loading triggered by brittle fracture at cryogenic
}

\section{condition}

Jeom Kee Paik ${ }^{\mathrm{a}, \mathrm{b}, \mathrm{c}^{*}}$, Dong Hun Lee ${ }^{\mathrm{b}}$, Sung Hwan Noh ${ }^{\mathrm{b}}$, Dae Kyeom Park ${ }^{\mathrm{a}}$, and Jonas W. Ringsberg ${ }^{\mathrm{d}}$

${ }^{a}$ The Korea Ship and Offshore Reseach Institute (Lloyd's Register Foundation Research Centre of Excellence), Pusan National University, Busan, Republic of Korea; ${ }^{\mathrm{b}}$ Department of Mechanical Engineering, University College London, London, UK; ${ }^{c}$ Department of Naval Architecture and Ocean Engineering, Pusan national University, Busan, Republic of Korea; ${ }^{\mathrm{d}}$ Department of Mechanics and Maritime Sciences, Chalmers Univeristy of Technology, Gothenburg, Sweden

* Corresponding author. J.K. Paik. Email: j.paik@ucl.ac.uk

\begin{abstract}
This paper is a sequel to the authors' earlier article (Paik et al. 2020a, Full-scale collapse testing of a steel stiffened plate structure under cyclic axial-compressive loading, Structures, https://doi.org/10.1016/j.istruc.2020.05.026). The aim of the paper was to present a test data on the ultimate compressive strength characteristics of a full-scale steel stiffened plate structure at cryogenic condition which may be due to unwanted release of liquefied gases. Steel plate panels of an as-built containership carrying 1,900 TEU were referenced for this purpose. The test structure was fabricated in a shipyard using exactly the same welding technology as used in today's shipbuilding industry. It is observed that the test structure reaches the ultimate limit states triggered by brittle fracture, which is totally different from typical collapse modes at room temperature. Details of the test database are documented as they can be used to validate computational models for the structural crashworthiness analysis involving brittle fracture at cryogenic condition.
\end{abstract}

Keywords: Full-scale collapse testing, cryogenic condition, brittle fracture, steel stiffened plate structure, ultimate compressive strength, liquefied gas release

\section{Introduction}

Steel stiffened plate panels are used in naval, offshore, mechanical and civil engineering structures as their primary strength parts. While in service, there may be hazardous situation that such structures are exposed to cryogenic condition due to unwanted release of liquefied gases: Liquefied gas carriers are used to transport natural and hydrogen gases at sea. While the building history of LNG (liquefied natural gas) carriers is long, the world's first liquefied hydrogen carrier was launched in 2019 at Kawasaki Heavy Industries' Kobe Works shipyard in Japan. The vessel, 
named Suiso Frontier, is due for completion in late 2020 and will be equipped with a 1,250 cubic meters of liquefied hydrogen cooled to $-253{ }^{\circ} \mathrm{C}$.

(https://www.maritime-executive.com/article/world-s-first-

liquefied-hydrogen-carrier-launched). Natural or hydrogen gas is increasingly used as energy source. To efficiently transport or manage such gases, they are usually liquefied at cryogenic condition while keeping atmospheric pressure because the liquefaction of gases can reduce the volume by $1 / 600$. Natural gas can be liquefied at a temperature below $-161.5^{\circ} \mathrm{C}$ at $1 \mathrm{~atm}$, while hydrogen gas is liquefied at $-253^{\circ} \mathrm{C}$. It is noted that another way to liquefy gases is also applicable by compressing them with high pressure. In addition, LNG is now also adopted as an alternative of fuels for ship propulsion in association with the issues of $\mathrm{CO}_{2}$ emissions. There are always hazards that liquefied gases at cryogenic condition are released from cargo containments or fuel tanks of ships (Petti et al. 2013), as illustrated in Figure 1. Similar hazards can also be considered in bunkering of liquefied gases at cryogenic condition to ships or offshore power plants (Park et al. 2020).
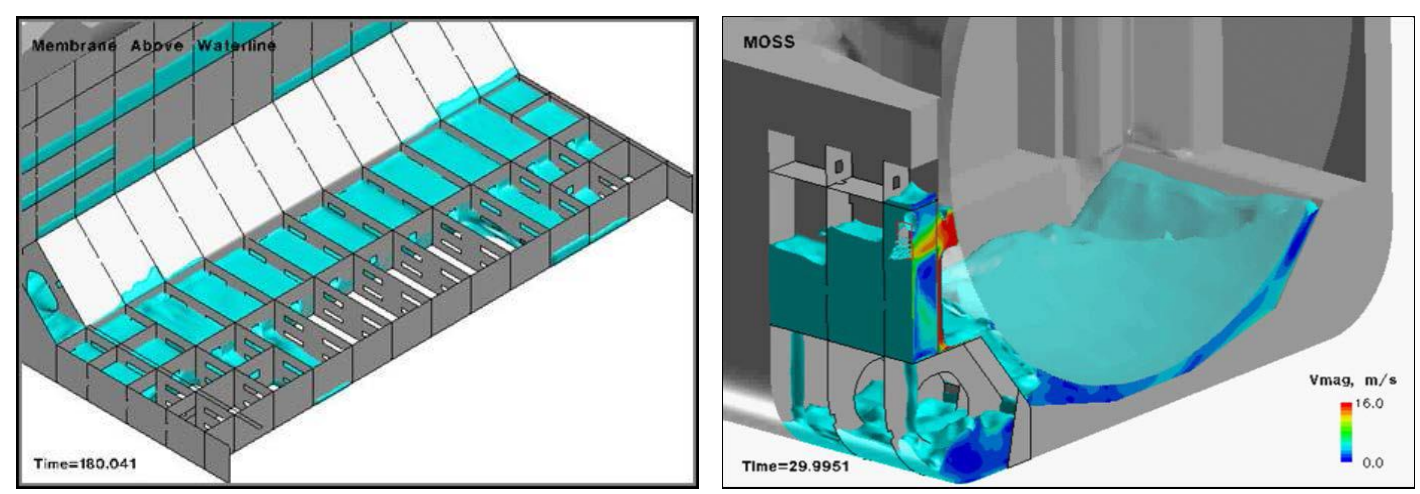

Figure 1. Release of liquefied natural gas to ship structures (Petti et al. 2013).

Hull structures are made of carbon steels which are very vulnerable to the exposure of liquefied gases because metals at cryogenic condition tend to become fragile due to brittle fracture. Steel stiffened plate structures form a main body of ship's hull structures and the ultimate limit states associated with buckling and plastic collapse are now used as their primary design criteria for structural scantlings and arrangements (Hughes and Paik 2013, Paik 2018). With the current and future trend of shipping, however, a great attention on the ultimate limit states triggered by brittle fracture must be paid in association with accidental scenarios that steel structures are exposed to cryogenic condition due to liquefied gas release.

The aim of the present study is to experimentally examine the characteristics of the ultimate limit state for steel stiffened plate structures exposed to cryogenic condition associated with an accidental scenario due to unwanted release of liquefied gases. The study presents a full-scale physical model test on a steel stiffened plate structure under axial compressive loads conducted at room temperature and at cryogenic condition, and compares with a similar test but at room temperature which is described in a separate paper (Paik et al. 2020a). As the primary load component, axial compressive loads representative for either deck structures in sagging or bottom structures in 
hogging, are applied to investigate the failure modes of the test structures involving brittle fracture as well as buckling and plastic collapse.

It should be emphasized that full- or larger-scale physical models is always demanding in contrast to small-scale models because scaling laws are not available to convert small-scale models to full-scale prototype structures in association with highly nonlinear aspects due to multiple physics, collapse and fracture phenomena.

Large-scale or full-scale test data on the collapse of steel stiffened plate structures is available in the literature (Smith 1976, Dow 1991, Ifayefunmi 2014, Iijima et al. 2015, Tanaka et al. 2015, Paik et al. 2020b, 2020c). To the best knowledge of the authors, however, no contributions to a similar study at low (sub-zero) temperatures or cryogenic condition are available in the literature. As such, the present study contributes to the development of a test database of the ultimate compressive strength of full-scale steel stiffened plate structures. The results presented in the paper can be used to validate computational models for the structural crashworthiness analysis involving brittle fracture at cryogenic condition.

\section{Ultimate compressive strength characteristics of plate panels for as-built ships}

To design the test structure, the ultimate compressive strength characteristics of plate panels for as-built ships were investigated. The main body of hull structures is formed by stiffened plate structures as shown in Figure 2, with support members (longitudinal stiffeners and transverse frames) denoted by the nomenclature indicated in Figure 3.

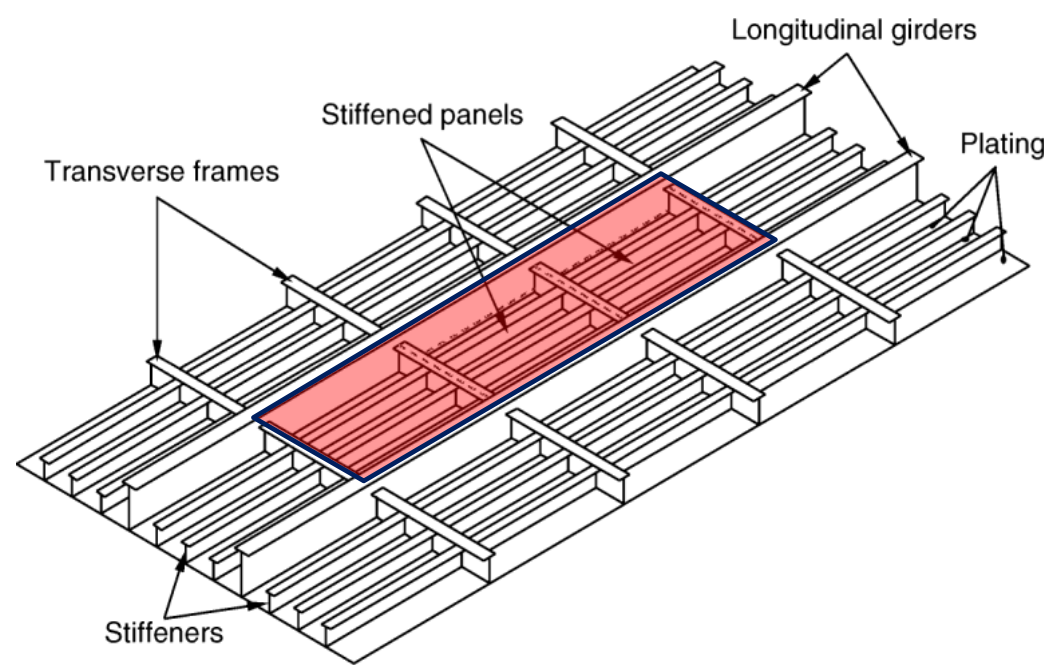

Figure 2. A typical steel stiffened plate structure in ships and ship-shaped offshore installations. 

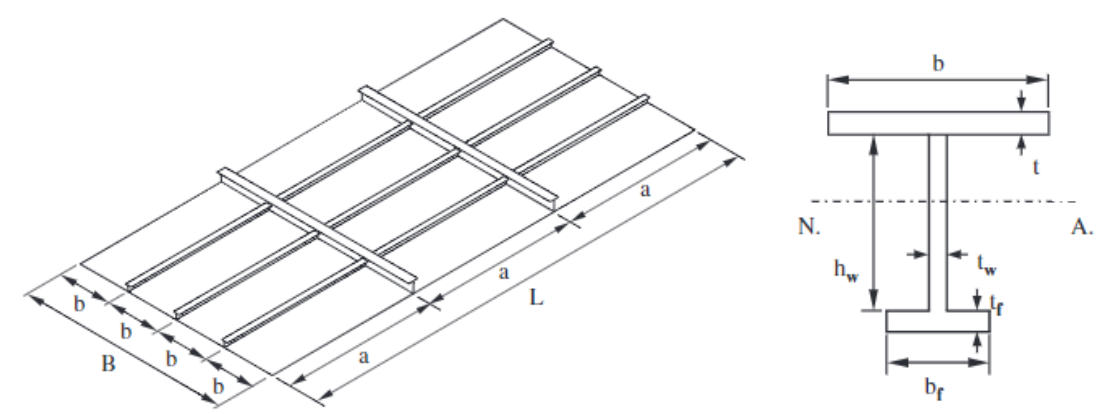

Figure 3. Nomenclature of the dimensions for a stiffened plate structure with a typical type of support member.

The structural characteristics of plate panels can be identified by the plate slenderness ratio, $\beta$, and the column slenderness ratio of the longitudinal stiffeners attached to the plating, $\lambda$ (Paik 2018). These parameters are defined as:

$$
\begin{gathered}
\beta=\frac{b}{t} \sqrt{\frac{\sigma_{Y p}}{E}} \\
\lambda=\frac{a}{\pi r} \sqrt{\frac{\sigma_{Y e q}}{E}}
\end{gathered}
$$

where $a$ is the length of the plate (or spacing between the transverse frames), $b$ is the breadth of the plate (or spacing between the longitudinal stiffeners), $t$ is the thickness of the plate, $E$ is the Young's modulus, $\sigma_{Y p}$ is the yield stress of the plate's material, and $r$ is the radius of gyration of the longitudinal stiffener with the attached plating, which is calculated from $r=\sqrt{I / A}$ where $I$ is the moment of inertia and $A$ is the cross-sectional area.

The yield strength of stiffeners is often different from that of plating. In Equation (2), $\sigma_{Y e q}$ is the equivalent yield strength over the cross section of the stiffeners with attached plating which is given with the nomenclature in Figure 3 as follows:

$$
\sigma_{Y e q}=\frac{b t \sigma_{Y p}+\left(h_{w} t_{w}+b_{f} t_{f}\right) \sigma_{Y s}}{b t+h_{w} t_{w}+b_{f} t_{f}}
$$

where $\sigma_{Y S}$ is the yield strength of stiffener.

Figures 4 and 5 present the variety of the geometric properties for plate panels of as-built containerships or oil tankers with varying their size, respectively. It is found that the plate slenderness ratio is in the range of $0.5-5.0$, while the column slenderness ratio (with attached plating) is in the range of $0.25-1.0$. One of features found from ultra-large containerships is that the column slenderness ratio for a 22,000 TEU containership is comparatively larger than other smaller containerships. This 
may be due to the efforts for minimizing structural weight of such an ultra-large containership, but a great attention needs to be paid for the robust structural design with tolerance against extreme conditions (Hughes and Paik 2013, Paik 2018, 2019, Paik et al. 2019, Lee and Paik 2020).

(a)

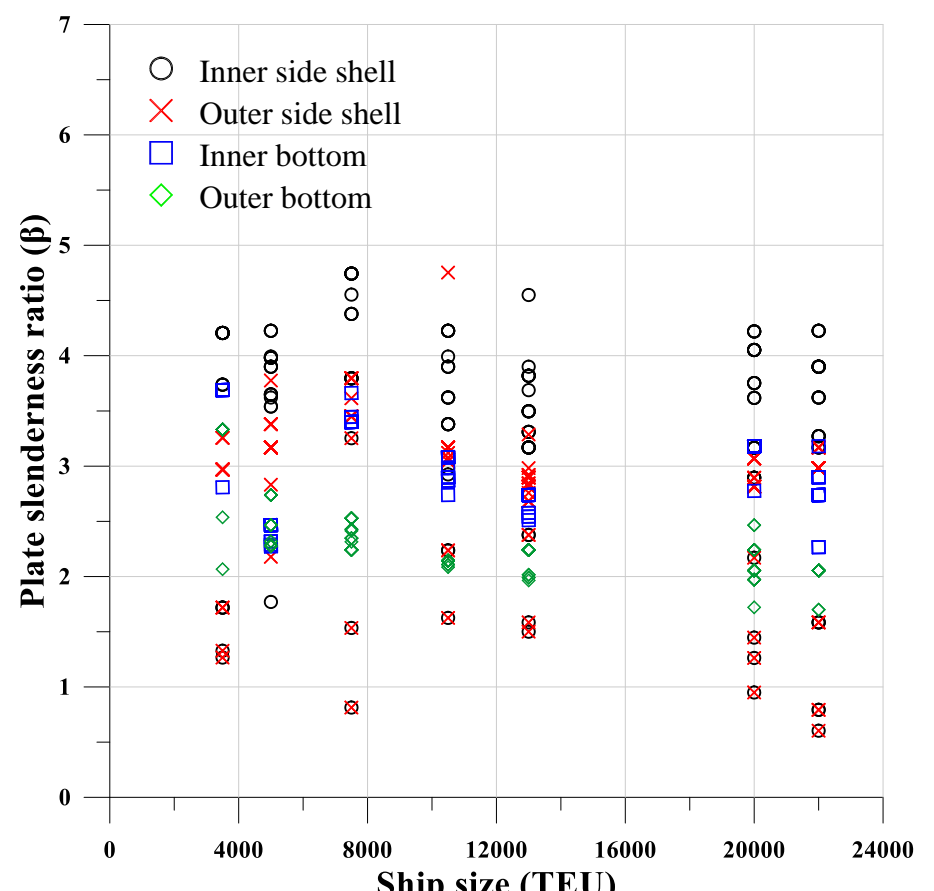

Ship size (TEU)

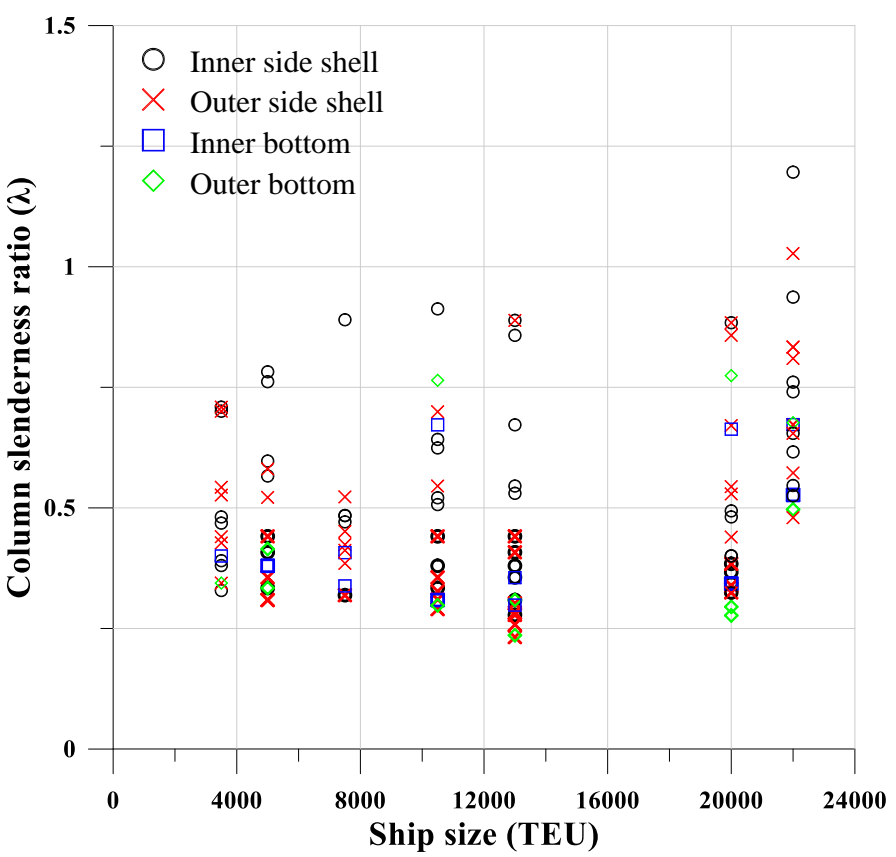

(b) Ship size (TEU)

Figure 4. Variety of the geometric properties of plate panels with the size of as-built containerships: (a) plate slenderness ratio, (b) column slenderness ratio. 


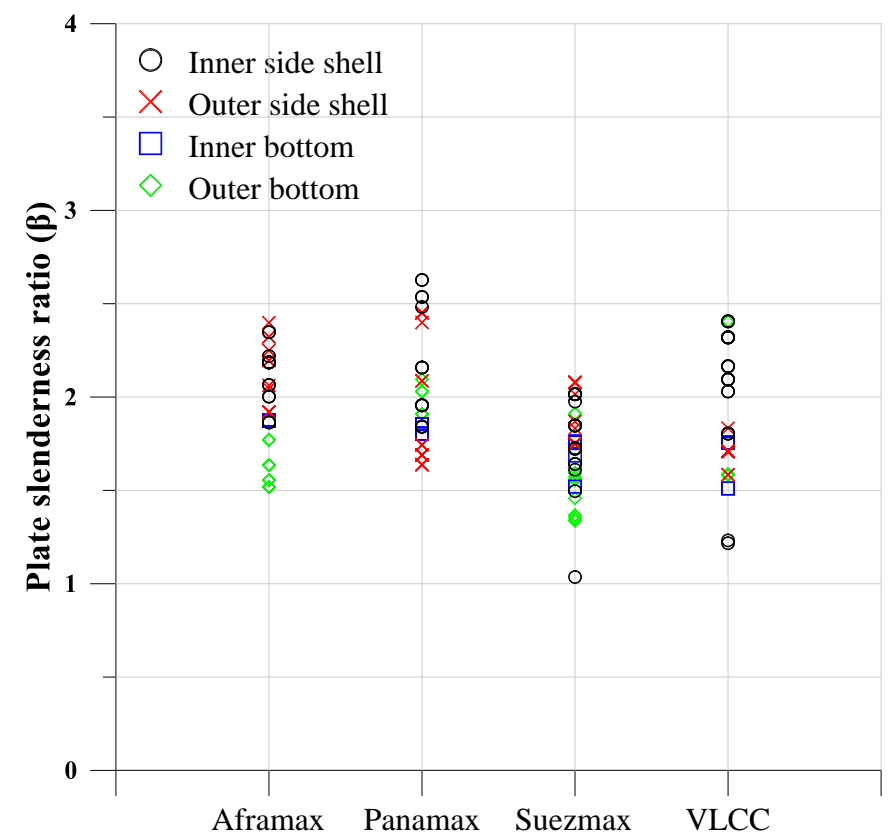

(a)

Ship size

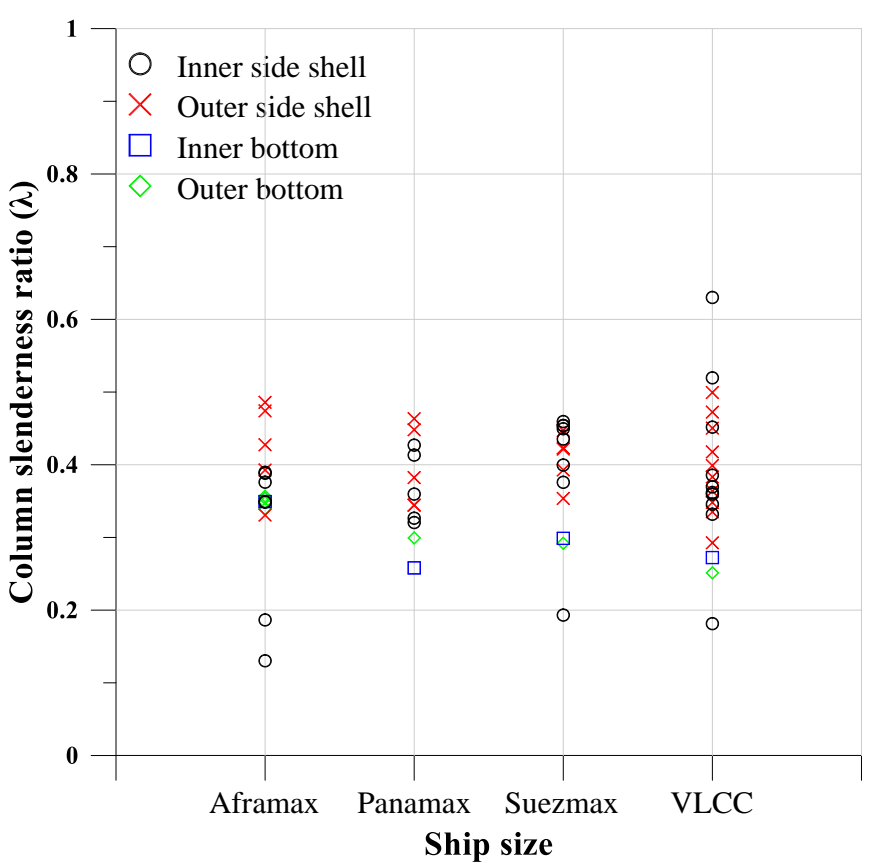

(b) Ship size

Figure 5. Variety of the geometric properties of plate panels with the size of as-built oil tankers: (a) plate slenderness ratio, (b) column slenderness ratio.

The plate and column slenderness ratios are important in the analysis of collapse modes. For a steel or aluminium stiffened plate structure at room temperature, Paik (2018) categorized the collapse modes into the following six types:

- Mode I: Overall collapse of the plate and the stiffeners as a unit

- Mode II: Plate collapse without distinct failure of the stiffeners

- Mode III: Beam-column type collapse

- Mode IV: Collapse by local web buckling of stiffener(s) 
- Model V: Collapse by lateral-torsional buckling (tripping) of stiffener(s)

- Mode VI: Gross yielding

Figure 6 presents the collapse modes of inner or outer bottom plate panels under predominantly axial compressive loads for 31 as-built containerships and 11 as-built oil tankers, obtained by ALPS/ULSAP (2019) which is a computer program for the ultimate strength analysis of plates and stiffened plate structures under combined biaxial compression / tension, edge shear, lateral pressure loads and in-plane bending moments using analytical solutions presented in Paik (2018).

It is observed from Figure 6 that bottom plate panels of oil tankers reach the ultimate limit state by collapse mode V. For bottom plate panels of containerships, collapse mode V dominates the ultimate limit state while collapse modes III and IV are also observed for some plate panels. Based on these computations and observations, the test structure was designed so that it will reach its ultimate limit state at room temperature by collapse mode $\mathrm{V}$, which is regarded as a representative collapse mode of ship bottom plate panels.

(a)
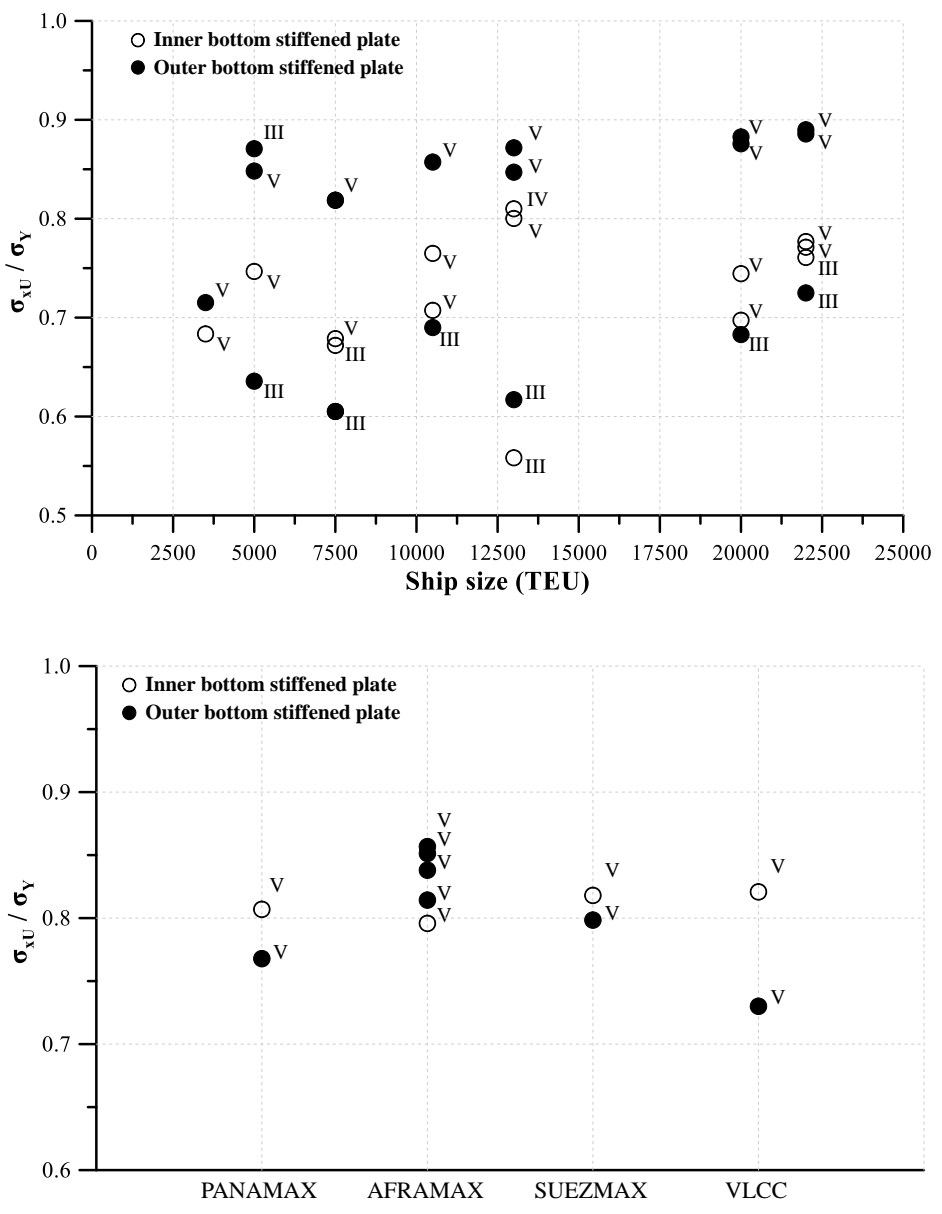

(b)

Ship size (Class)

Figure 6. Collapse modes of inner and outer bottom plate panels under axial compressive loads, obtained from ALPS/ULSAP: (a) for 31 as-built containerships, (b) for 11 as-built oil tankers. 


\section{Design of the test structure}

The test structure was designed as a plate panel of an as-built 1,900 TEU containership shown in Figure 7. It has two transverse frames and four longitudinal stiffeners, as shown in Figure 8. The 3-bay plate panel model is adopted as it makes possible to take into account the effects of transverse frames in terms of deflections and rotational restraints associated with the continuous bays of plate panels.

The testing aimed at investigating the failure mode(s) of the panel with a focus on its central bay; hence, prior failure of the outer two bays should be avoided. As such, the web thickness of the longitudinal stiffeners at the outer two bays of the plate panel is $20 \mathrm{~mm}$, while it is $10 \mathrm{~mm}$ at the central bay. Also, the plate of the test structure is extended $240 \mathrm{~mm}$ on both sides in the transverse direction so that the unloaded edges in the longitudinal direction of the structure can be supported by rigid jigs; see Section 6.

Table 1 summarizes the dimensions of the plate panels for the reference vessel versus the test structure. The plate panels are both made of high tensile steel with grade AH32; the nominal values of the material properties are presented in Table 2. The ultimate compressive strengths of the plate panels were predicted by the ALPS/ULSAP (2019) program. The results are presented in Table 1, confirming that the test structure is almost the same as the reference structure in scantlings and structural characteristics including collapse mode V (tripping).

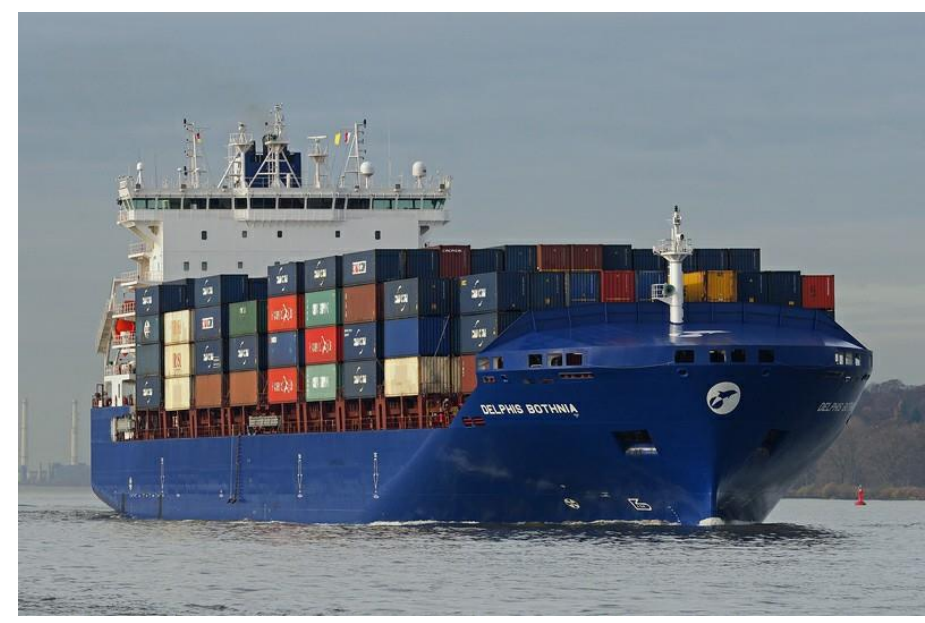

Figure 7. The reference vessel used in this study, a 1,900 TEU containership built by Hanjin Heavy Industries, Busan, South Korea. 


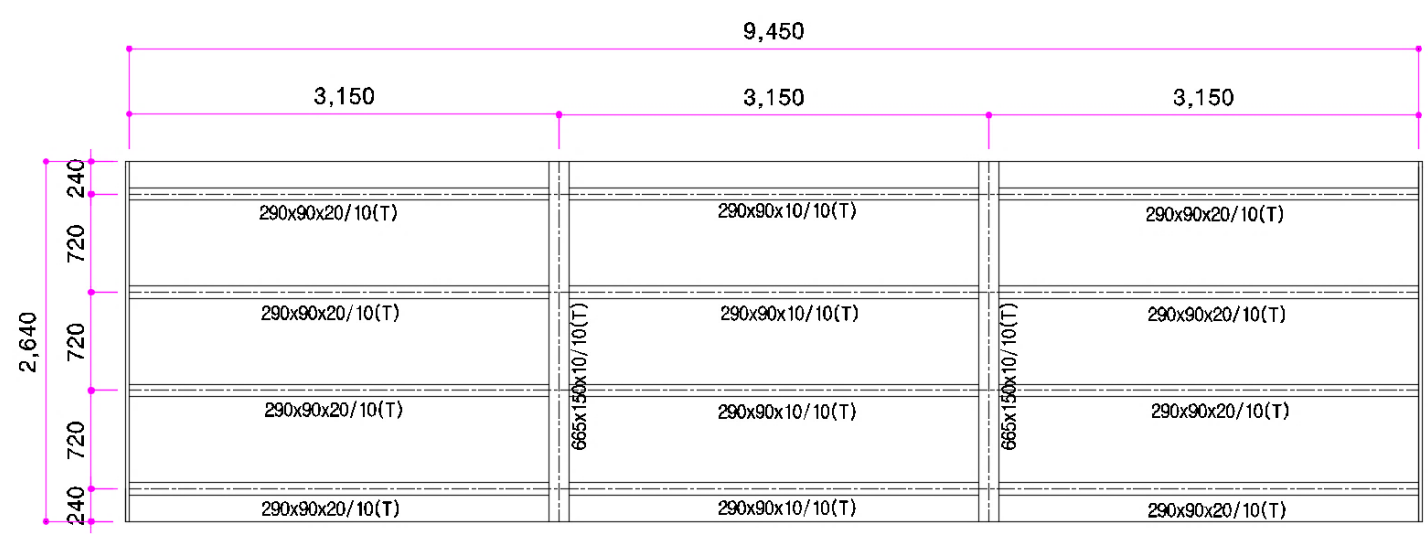

Figure 8. Structural drawing of the test structure (unit: $\mathrm{mm}$ ).

Table 1. Dimensions of the plate panel structures for the reference vessel versus the test structure.

\begin{tabular}{|c|c|c|}
\hline Parameter & Reference structure & Test structure \\
\hline Material & AH32 & AH32 \\
\hline Length of plate panel, $L$ & $9450 \mathrm{~mm}$ & $9450 \mathrm{~mm}$ \\
\hline $\begin{array}{l}\text { Spacing between } \\
\text { transverse frames, } a\end{array}$ & $3150 \mathrm{~mm}$ & $3150 \mathrm{~mm}$ \\
\hline Breadth of plate panel, $B$ & $2640 \mathrm{~mm}$ & $2640 \mathrm{~mm}$ \\
\hline $\begin{array}{l}\text { Spacing between } \\
\text { longitudinal stiffeners, } b\end{array}$ & $864 \mathrm{~mm}$ & $720 \mathrm{~mm}$ \\
\hline Plate thickness, $t$ & $12 \mathrm{~mm}$ & $10 \mathrm{~mm}$ \\
\hline Plate slenderness ratio, $\beta$ & 2.89 & 2.89 \\
\hline $\begin{array}{l}\text { Dimensions of } \\
\text { longitudinal stiffener(s), } \\
h_{w} \times b_{f} \times t_{w} / t_{f}\end{array}$ & $283 \times 90 \times 13 / 17(\mathrm{~T})(\mathrm{mm})$ & $290 \times 90 \times 10 / 10(\mathrm{~T})(\mathrm{mm})$ \\
\hline $\begin{array}{l}\text { Dimensions of transverse } \\
\text { frame(s), } h_{w} \times b_{f} \times t_{w} / t_{f}\end{array}$ & $665 \times 150 \times 10 / 10(\mathrm{~T})(\mathrm{mm})$ & $665 \times 150 \times 10 / 10(\mathrm{~T})(\mathrm{mm})$ \\
\hline $\begin{array}{l}\text { Column slenderness ratio, } \\
\lambda\end{array}$ & 0.38 & 0.38 \\
\hline Mass of test structure & 4.670 ton & 3.994 ton \\
\hline Collapse mode & $\mathrm{V}$ & $\mathrm{V}$ \\
\hline $\begin{array}{l}\text { Ultimate compressive } \\
\text { strength at room } \\
\text { temperature, predicted by } \\
\text { ALPS/ULSAP }\end{array}$ & $238.94 \mathrm{MPa}$ & $225.96 \mathrm{MPa}$ \\
\hline
\end{tabular}




\section{Mechanical properties of the material}

Plate sheets of high tensile steel with grade AH32 were procured under the responsibility of a shipyard in Busan, South Korea, which built the test structure. Table 2 presents the nominal values of the material properties at room temperature provided by the steel maker of the AH32 high tensile steel, which meet the minimum requirements for ship structural materials specified by ASTM A131/A131M (ASTM 2019).

The rolling or normal direction of $\mathrm{V}$-notch Charpy impact tests indicated in Table 2 is illustrated in Figure 9. Figure 10 shows the percent brittle fracture and V-notch Charpy impact energy of a high tensile steel at different temperatures including room temperature and cryogenic condition, extracted from KSNA (1983). It is seen from Figure 10 that the fracture toughness characteristics of high tensile steel significantly decrease with a decrease in temperature, and the fracture toughness at weld metal is lower than that at base metal. This means that the fracture toughness is significantly affected by low temperatures, and a brittle-to-ductile transition region needs to be characterized (Kaminskji and Galatenko 1999, Berejnoi and Perez Ipiña 2015, Majzoobi et al. 2016, Bruchhausen et al. 2017, Li et al. 2019, Chen et al. 2020). Among them, Majzoobi et al. (2016) found that the transition temperature of high tensile steel from ductile to brittle fracture is about $-80{ }^{\circ} \mathrm{C}$. This important topic at a material level is however out of the scope of the paper, on which the failure (buckling and plastic collapse) at a structure level is focused.

Table 2. Nominal values of the mechanical properties for the AH32 high tensile steel.

\begin{tabular}{|c|c|c|c|c|c|}
\hline $\begin{array}{l}\text { Elastic } \\
\text { modulus, } \\
E(\mathrm{GPa})\end{array}$ & $\begin{array}{c}\text { Yield } \\
\text { strength, } \\
\sigma_{Y} \\
(\mathrm{MPa})\end{array}$ & $\begin{array}{c}\text { Ultimate } \\
\text { tensile } \\
\text { strength, } \\
\sigma_{T} \\
(\mathrm{MPa})\end{array}$ & $\begin{array}{c}\text { Fracture } \\
\text { (failure) } \\
\text { strain, } \\
\varepsilon_{f} \\
(-)\end{array}$ & $\begin{array}{l}\text { Poisson's } \\
\text { ratio } \\
(-)\end{array}$ & $\begin{array}{c}\text { V-notch Charpy impact } \\
\text { energy at } 0{ }^{\circ} \mathrm{C} \\
(\mathrm{J})\end{array}$ \\
\hline$\geq 200$ & $\geq 315$ & $440-590$ & $\geq 0.20$ & 0.3 & $\begin{array}{l}\text { Rolling direction: } 31 \\
\text { Normal direction: } 22\end{array}$ \\
\hline
\end{tabular}




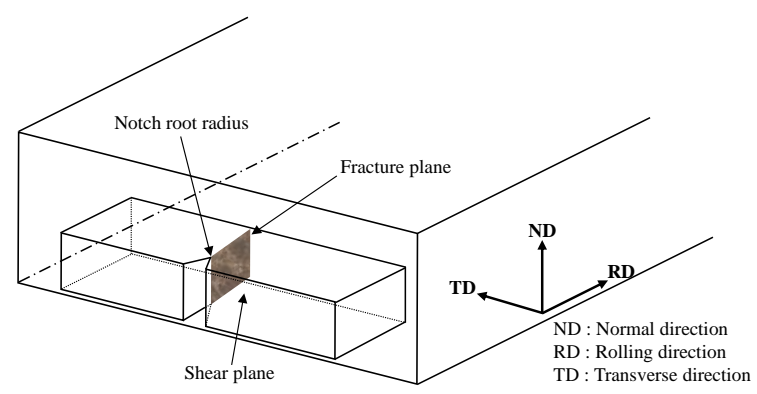

Figure 9. Extraction of V-notch Charpy impact test specimen from a plate sheet.

(a)
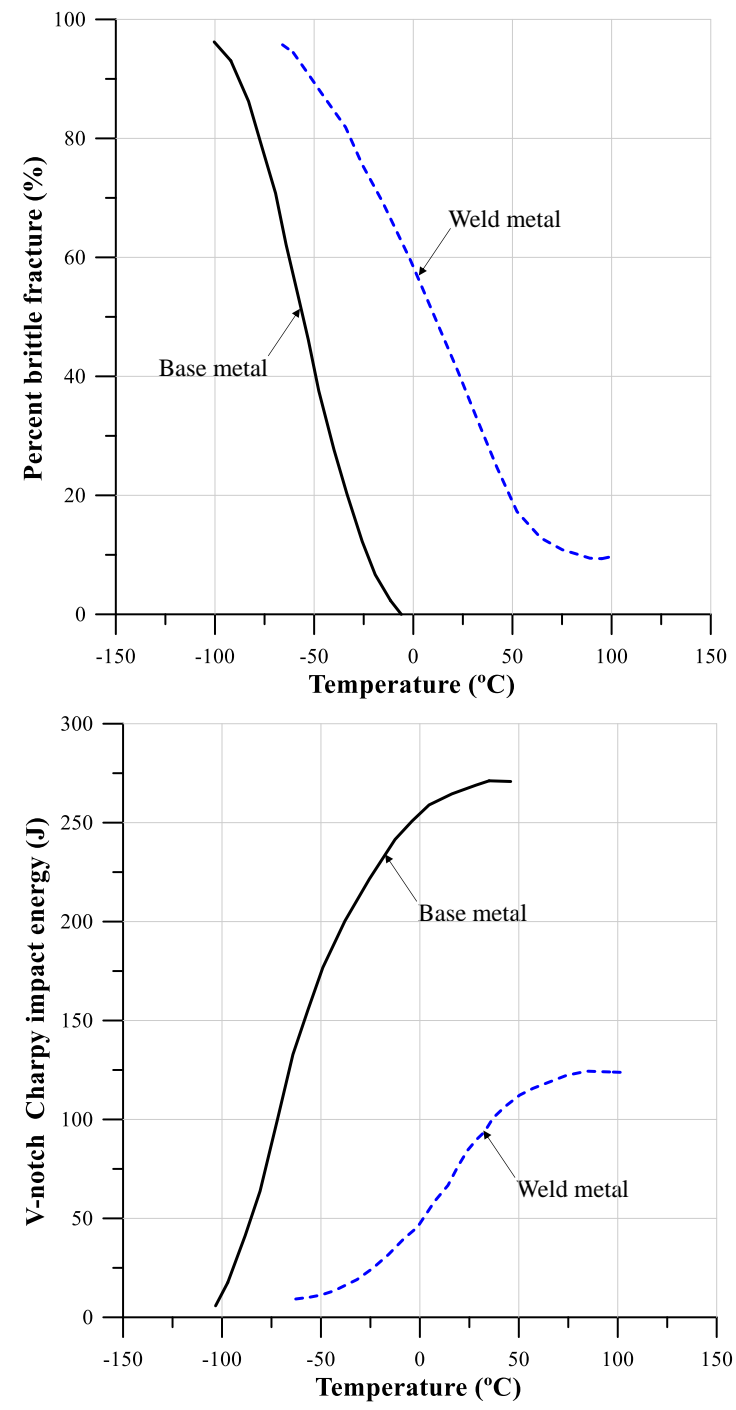

Figure 10. Fracture toughness characteristics of a high tensile steel: (a) percent brittle fracture, (b) V-notch Charpy impact energy; extracted from KSNA (1983).

It is obvious that the mechanical properties of the material used for fabricating the test structure are not identical to the nominal values even at room temperature. Furthermore, the effects of low temperatures on the material properties are not known. As such, the mechanical properties for the AH32 high tensile steel were obtained from 
material testing in this study, where multiple specimens (two specimens for tension tests and three specimens for compression tests) per each temperature were tested to minimize unwanted uncertainties. The results were post-processed and stored in a database for other researchers in association with the software MPDAS (Paik et al. 2017).

At room temperature, the Bauschinger effect (Brockenbrough and Johnston 1981) is often neglected, and the engineering stress-engineering strain curves of a material are usually obtained in tension condition with a presumption that the material behaviour in compression is the same as in tension. For this case, the tensile coupon test specimen as shown in Figure 11(a) is used as per ASTM E8 (ASTM 2015). At low temperature or cryogenic condition, however, the mechanical properties of a material in tension may differ from those in compression. The tensile behaviour at low temperatures can still be characterized using a tensile coupon type specimen, but the compressive behaviour at low temperatures is characterized using a test specimen with a round rod type as shown in Figure 11(b) in compliance with ASTM E9 (ASTM 2018).

Figure 12 shows a test set-up for material testing by universal test machine, where a cooling chamber with liquefied nitrogen gases is used to attain low temperatures. Figure 13 illustrates the process according to the ISO 6892-3 (ISO 2015) standard to lower the temperature in a material test, e.g., using liquefied nitrogen gases. The surface temperature of the specimen placed inside the cooling chamber was measured using thermo-electric couple sensor. After the surface temperature of the specimen reached the target temperature, the material test started with 30 minutes of soaking time, where the cooling rate was $-5^{\circ} \mathrm{C} / \mathrm{min}$.

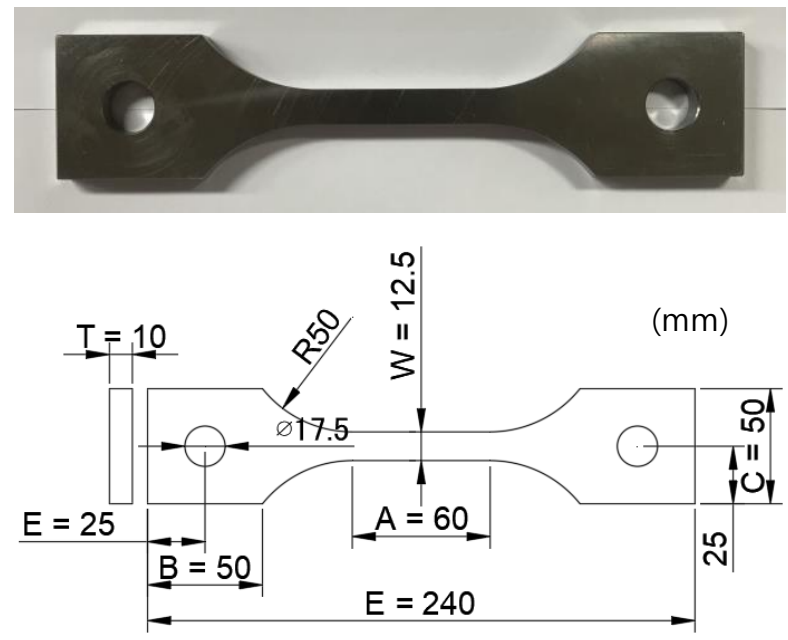

(a) Coupon type specimen for tension test 

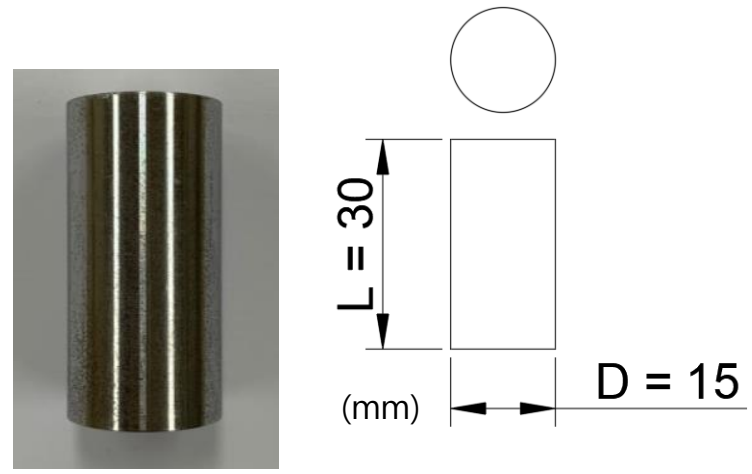

(b) Round rod type specimen for compression test

Figure 11. Test specimens used for characterization of the mechanical properties of the AH32 high tensile steel.

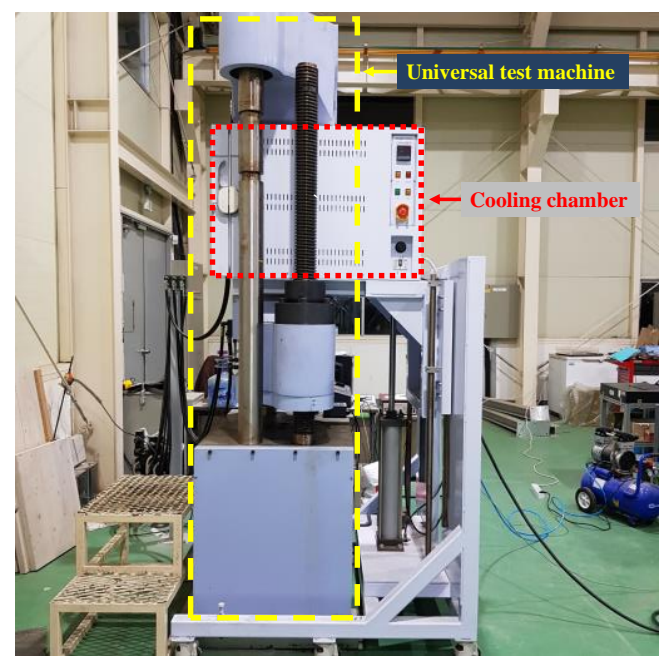

Figure 12. Set-up for material test in tension or compression with universal test machine and cooling chamber with liquefied nitrogen gases.

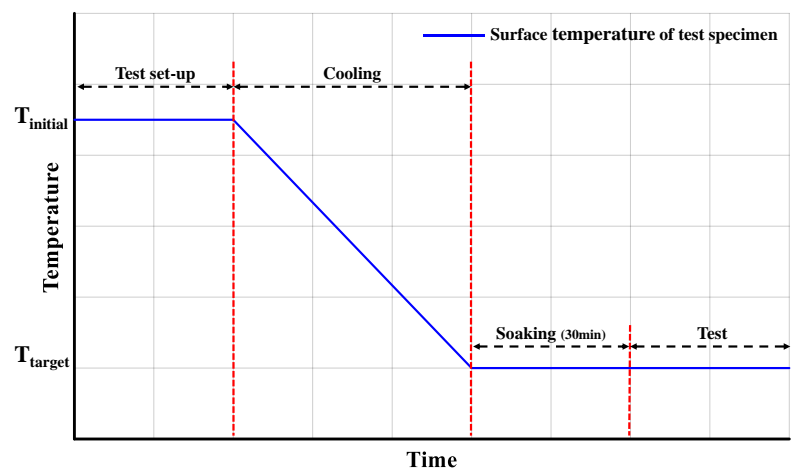

Figure 13. Process of lowering temperature in the material tests.

The loading speed in the material tests in either tension or compression was quasi-static with a strain rate of $0.001 / \mathrm{s}$ or almost zero strain rate. Figure 14 shows the tensile behaviour (engineering stress versus engineering strain curves) of the AH32 high tensile steel with varying low temperatures. Table 3 summarizes the average 
values of the material properties obtained from the tension tests based on two specimens for each temperature.

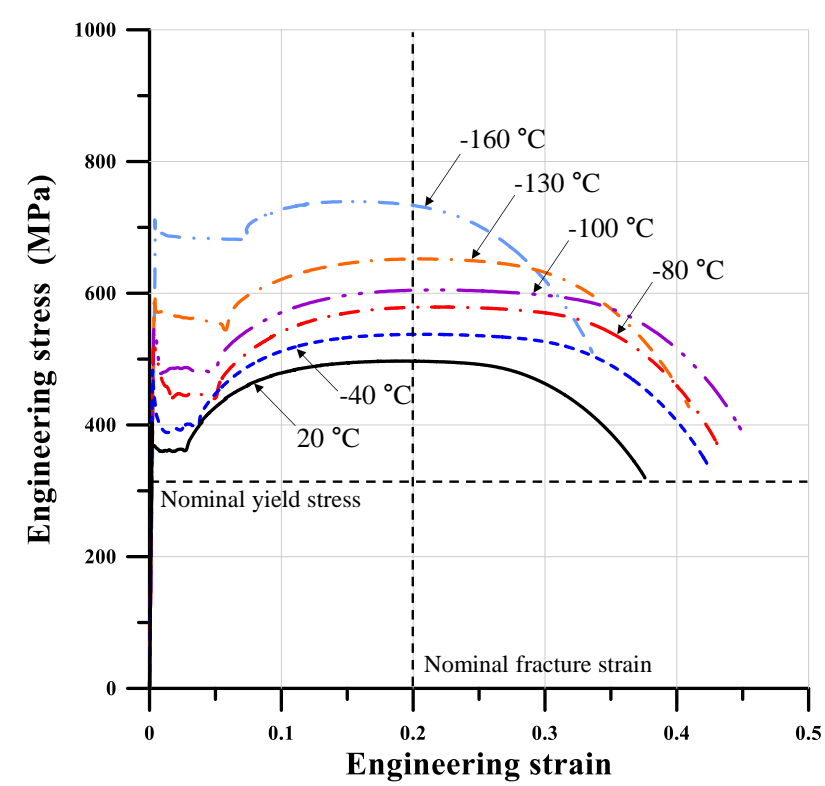

Figure 14. Tensile behaviour at different temperatures for the AH32 high tensile steel.

Table 3. Mechanical properties obtained from tension tests at different temperatures for the AH32 high tensile steel.

\begin{tabular}{|l|l|l|l|l|l|l|}
\hline \multicolumn{1}{|c|}{ Property } & $20^{\circ} \mathrm{C}$ & $-40^{\circ} \mathrm{C}$ & $-80^{\circ} \mathrm{C}$ & $-100^{\circ} \mathrm{C}$ & $-130^{\circ} \mathrm{C}$ & $-160^{\circ} \mathrm{C}$ \\
\hline $\begin{array}{l}\text { Elastic } \\
\text { modulus, } \\
(\mathrm{GPa})\end{array}$ & 205.8 & 205.8 & 205.8 & 205.8 & 205.8 & 205.8 \\
\hline $\begin{array}{l}\text { Yield } \\
\text { strength, } \sigma_{Y} \\
(\mathrm{MPa})\end{array}$ & 358.03 & 391.02 & 433.48 & 472.52 & 546.74 & 672.96 \\
\hline $\begin{array}{l}\text { Ultimate } \\
\text { tensile } \\
\text { strength, } \sigma_{T} \\
(\mathrm{MPa})\end{array}$ & 497.07 & 537.81 & 579.13 & 605.10 & 652.28 & 739.36 \\
\hline $\begin{array}{l}\text { Ultimate } \\
\text { tensile strain, } \\
\varepsilon_{T}\end{array}$ & 0.193 & 0.207 & 0.222 & 0.223 & 0.211 & 0.163 \\
\hline $\begin{array}{l}\text { Fracture } \\
\text { strain }(-), \varepsilon_{f}\end{array}$ & 0.376 & 0.423 & 0.430 & 0.448 & 0.409 & 0.336 \\
\hline
\end{tabular}


Figure 15 shows the changing trends of the mechanical properties due to low temperatures, where the normalized factor denotes a ratio of the corresponding parameter at low temperature to that at room temperature. It is observed that the elastic modulus is not affected by the temperature, but both the yield strength and the ultimate tensile strength increase as temperatures decrease. The fracture strain at the ultimate tensile strength and elongation (fracture strain) increase until the temperature is higher than $-100^{\circ} \mathrm{C}$, but they tend to decrease at temperatures lower than $-100^{\circ} \mathrm{C}$. This observation is supported by the findings of Majzoobi et al. (2016) in terms of the temperature of ductile-to-brittle fracture transition at $-80^{\circ} \mathrm{C}$.

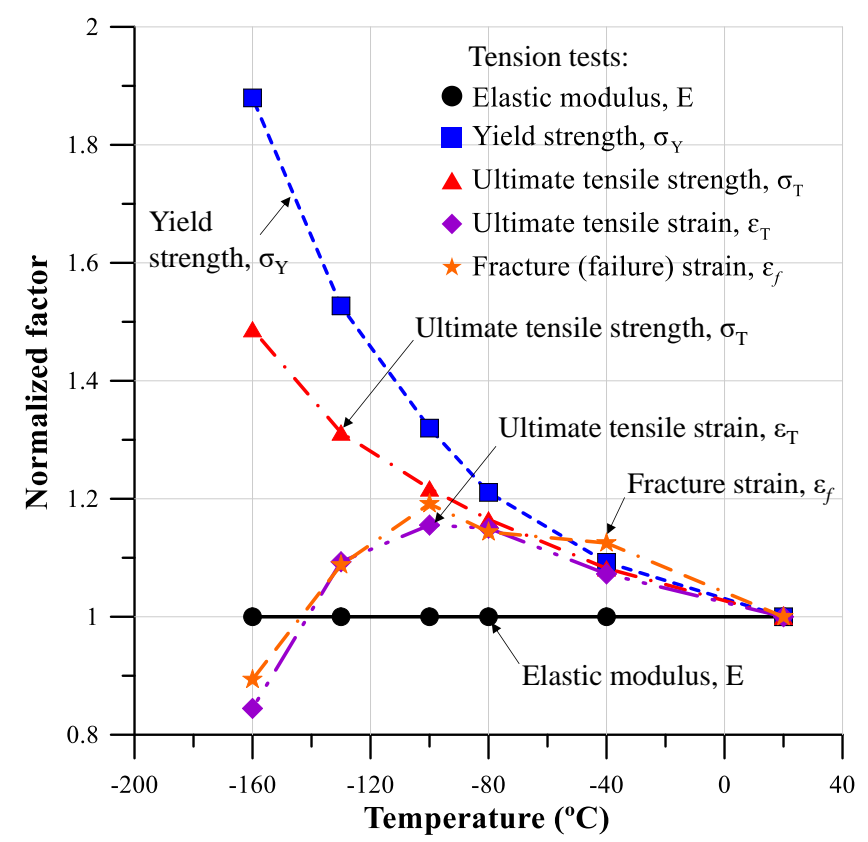

Figure 15. Variation of mechanical properties due to temperature for the AH32 high tensile steel from tension tests.

Figure 16 shows the compressive behaviour of the AH32 high tensile steel with varying temperature in terms of engineering stress versus engineering strain curves. Figure 16(a) shows the entire history of the compression tests and Figure 16(b) shows a close-up from the beginning of the tests until just after yield point is attained. In these tests at almost zero strain rate, no fracture happened despite low temperatures or cryogenic condition. Table 4 summarizes the average values of the material properties obtained from the compression tests based on three specimens for each temperature. It is observed that the elastic modulus is not affected by the temperature, but the yield strength increases as temperature decreases.

A comparison of the yield strengths in tension and compression tests is presented in Figure 17. The results show that the yield strength at room temperature is identical in both tension and compression, At low temperatures, however, the yield strength in tension is larger than that in compression and this trend becomes more severe as temperature decreases. It is obvious from these observations that the Bauschinger effect cannot be neglected at low (sub-zero) temperatures. 
Based on these results, obtained from the test database, the yield strength of the AH32 high tensile steel can be formulated as a polynomial as a function of the steel's temperature. In tension, it can be expressed by the following polynomial as:

$$
\frac{\sigma_{Y_{t}}}{\sigma_{Y, R T}}=7.9256 \times 10^{-10} T^{4}+5.7357 \times 10^{-8} T^{3}+1.4613 \times 10^{-5} T^{2}-0.0013 T+1.0189
$$

whereas in compression, it can be expressed as:

$$
\frac{\sigma_{Y c}}{\sigma_{Y, R T}}=2.6922 \times 10^{-6} T^{2}-0.0004 T+1.0076
$$

where $\sigma_{Y t}$ is the yield strength in tension, $\sigma_{Y c}$ is the yield strength in compression, $\sigma_{Y, R T}$ is the yield strength at room temperature, and $T$ is the temperature in ${ }^{\circ} \mathrm{C}$. The dotted lines in Figure 17 indicate Equation (4) or (5) for the corresponding tension or compression case, respectively.

On the other hand, useful parameters such as CTOD (crack tip opening displacement) or J-integral have been used to characterize the nonlinear material behaviour ahead of a crack tip in association with structural fracture mechanics, see chapter 9 of Paik (2018). However, these approaches are considered to be inadequate to compute the ultimate strength or crashworthiness of supersized structures under predominantly compressive loads.

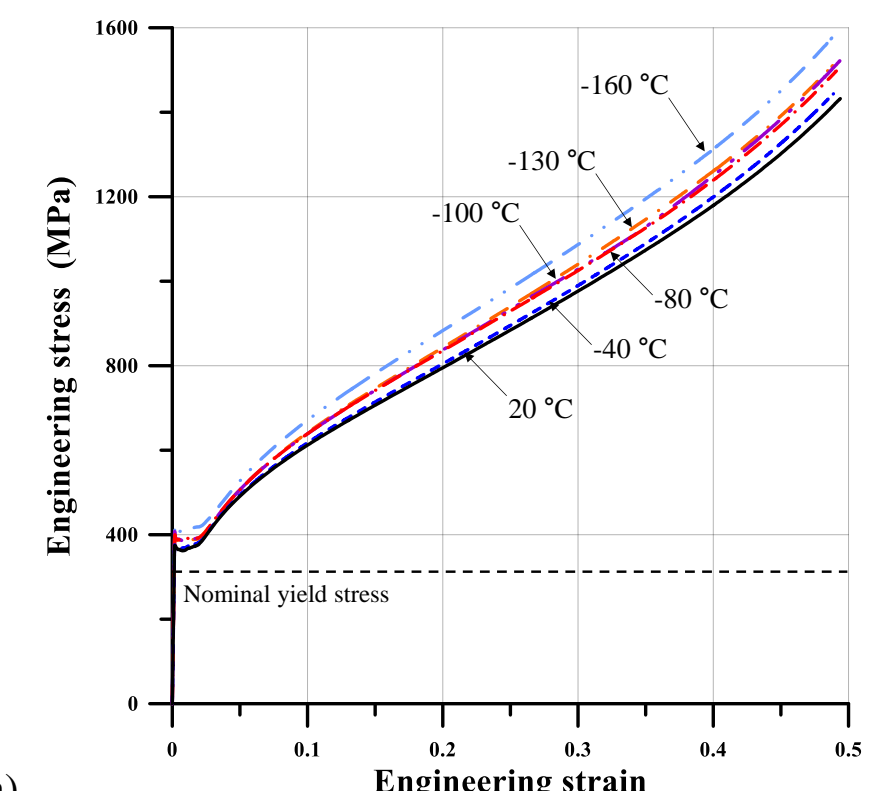

(a) 
(b)

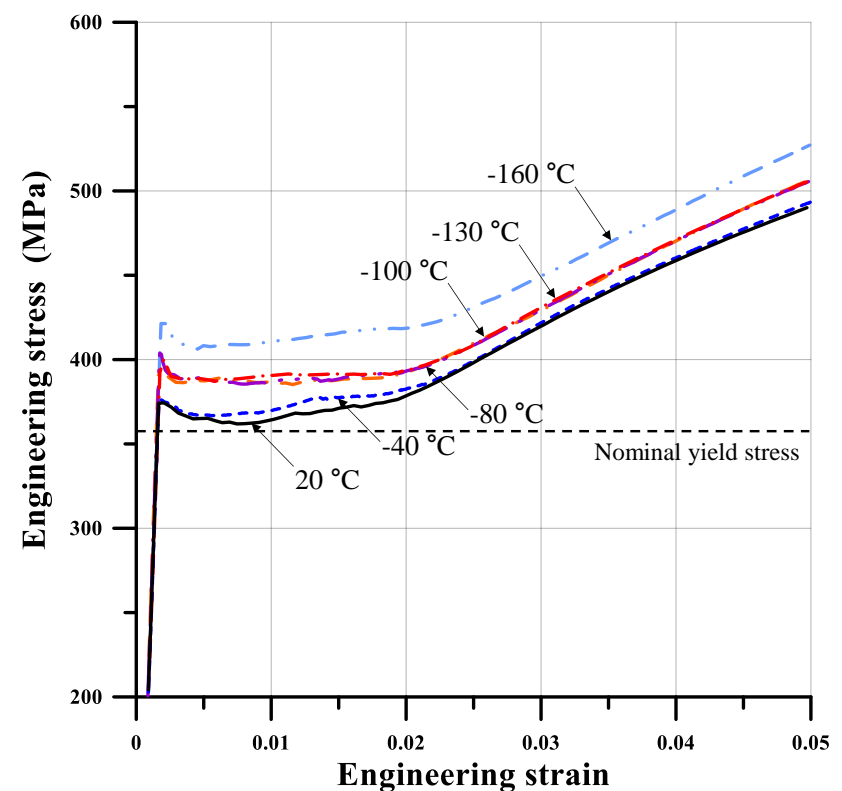

Figure 16. Compressive behaviour of the AH32 high tensile steel: (a) full stress-strain history, (b) close-up from start of test until after the yield strength has been reached.

Table 4. Mechanical properties of the AH32 high tensile steel obtained from compressive coupon testing at room and several lower (cold) temperatures.

\begin{tabular}{|l|l|l|l|l|l|l|}
\hline \multicolumn{1}{|c|}{ Property } & \multicolumn{1}{c|}{$20^{\circ} \mathrm{C}$} & $-40^{\circ} \mathrm{C}$ & $-80^{\circ} \mathrm{C}$ & $-100^{\circ} \mathrm{C}$ & $-130^{\circ} \mathrm{C}$ & $-160^{\circ} \mathrm{C}$ \\
\hline $\begin{array}{l}\text { Elastic } \\
\text { modulus, } E \\
(\mathrm{GPa})\end{array}$ & 205.8 & 205.8 & 205.8 & 205.8 & 205.8 & 205.8 \\
\hline $\begin{array}{l}\text { Yield } \\
\text { strength, } \sigma_{Y}\end{array}$ & 359.65 & 369.06 & 382.01 & 386.22 & 387.20 & 411.51 \\
$(\mathrm{MPa})$
\end{tabular}

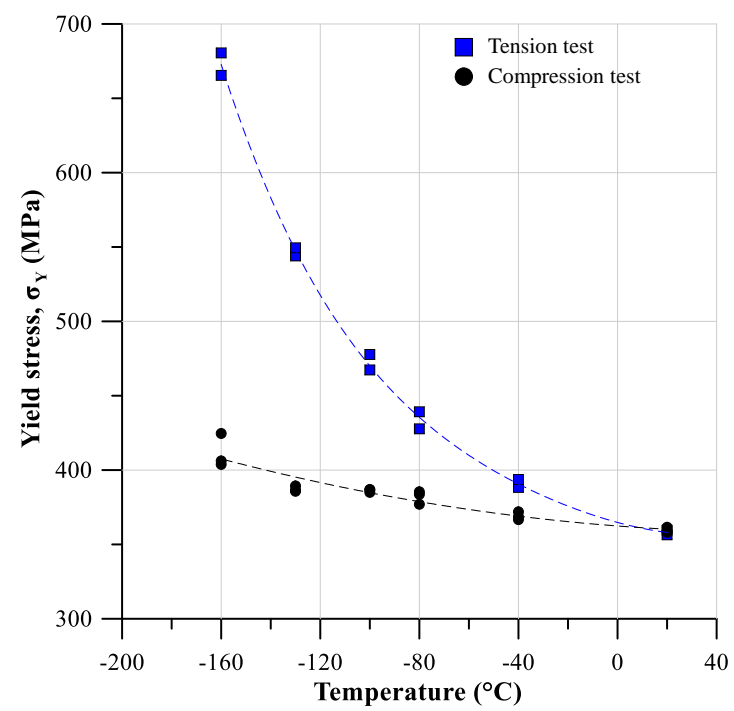

Figure 17. Variation of yield strength for the AH32 high tensile steel at low temperatures obtained from tension or compression tests. 


\section{Fabrication of the test structure}

The test structure was fabricated at a shipyard in Busan, South Korea, which builds small and medium merchant and patrol ships. By ordering the manufacturing of the test structure from a shipyard, it was ensured that it was fabricated under the same conditions as a real ship structure with regard to flame cutting and welding, among others.

Table 5 presents the welding conditions used during the fabrication of the test structure. To minimize the welding-induced initial imperfections, the plating of the test structure was entirely made of one full piece of a steel sheet, and hence, butt welds that connect pieces of steel sheets could be avoided. The longitudinal stiffeners and the transverse frames were attached to the plate by continuous fillet welding where the welding requirements of DNVGL (2018) are satisfied. The flux-cored arc welding (FCAW) method was used in accordance with the welding procedure specification requirements as indicated in Table 5.

Table 5. Welding conditions used during fabrication of the test structure.

\begin{tabular}{|l|l|}
\hline Method & FCAW \\
\hline Flux-cored wire & CSF-71S \\
\hline Leg length & $7 \mathrm{~mm}$ \\
\hline Current & $260 \mathrm{~A}(225 \sim 275 \mathrm{~A})$ \\
\hline Voltage & $28 \mathrm{~V}(23 \sim 32 \mathrm{~V})$ \\
\hline Welding speed & $30 \mathrm{~cm} / \mathrm{min}(24 \sim 34 \mathrm{~cm} / \mathrm{min})$ \\
\hline Heat input & $14.56 \mathrm{KJ} / \mathrm{cm}(7 \sim 18 \mathrm{KJ} / \mathrm{cm})$ \\
\hline
\end{tabular}

Note: A value within a parenthesis indicates the welding procedure specification requirements.

After a test structure was fabricated, the welding-induced initial imperfections in the form of initial deflections and residual stresses were measured using modern technologies such as a three dimensional scanner of structural geometry and an X-ray detector of stress. The details of their measurement data are presented in separate papers (Yi et al. 2020a, 2020b), where computational models to predict the welding-induced initial imperfections are also proposed together with their validation by comparison with the measured results.

\section{Test set-up}

The testing was conducted at the test site of the ICASS/KOSORI (www.icass.center) in Hadong, South Korea. Figure 18 shows a photo of the test set-up with the two dynamic loading actuators (among a total of three actuators available at the test site) used to apply the axial compressive loading. These loading actuators applied the dynamic compressive loading on one of the test structure's ends while its other end was restricted to move by a rigid reaction wall, as shown in the schematic in Figure 19. The maximum load capacity of each actuator is 1,000 ton. The loading speed of the actuators during the testing was kept at $0.25 \mathrm{~mm} / \mathrm{s}$. 
The two loading actuators were controlled by a personal computer to apply the axial compressive loads in a synchronized way so that a uniform axial displacement condition should always be secured in the longitudinal direction. A rigid jig with a thickness of $40 \mathrm{~mm}$ (see Figure 18) was attached at the heads of the loading actuators to ensure that the cross-section of the test structure remains in-plane. The unloaded edges of the plate panels were rigidly supported by a jig while in-plane movements in the transverse (plate width) direction were allowed as shown in Figure 20. A guide plate was added by bolting with the support jig to avoid twisting of unloaded edges and keep them straight. In order to minimize the friction forces in the contact between the test plate and the support jig along the unloaded edges, a low temperature lubricant was used on the plate surface.

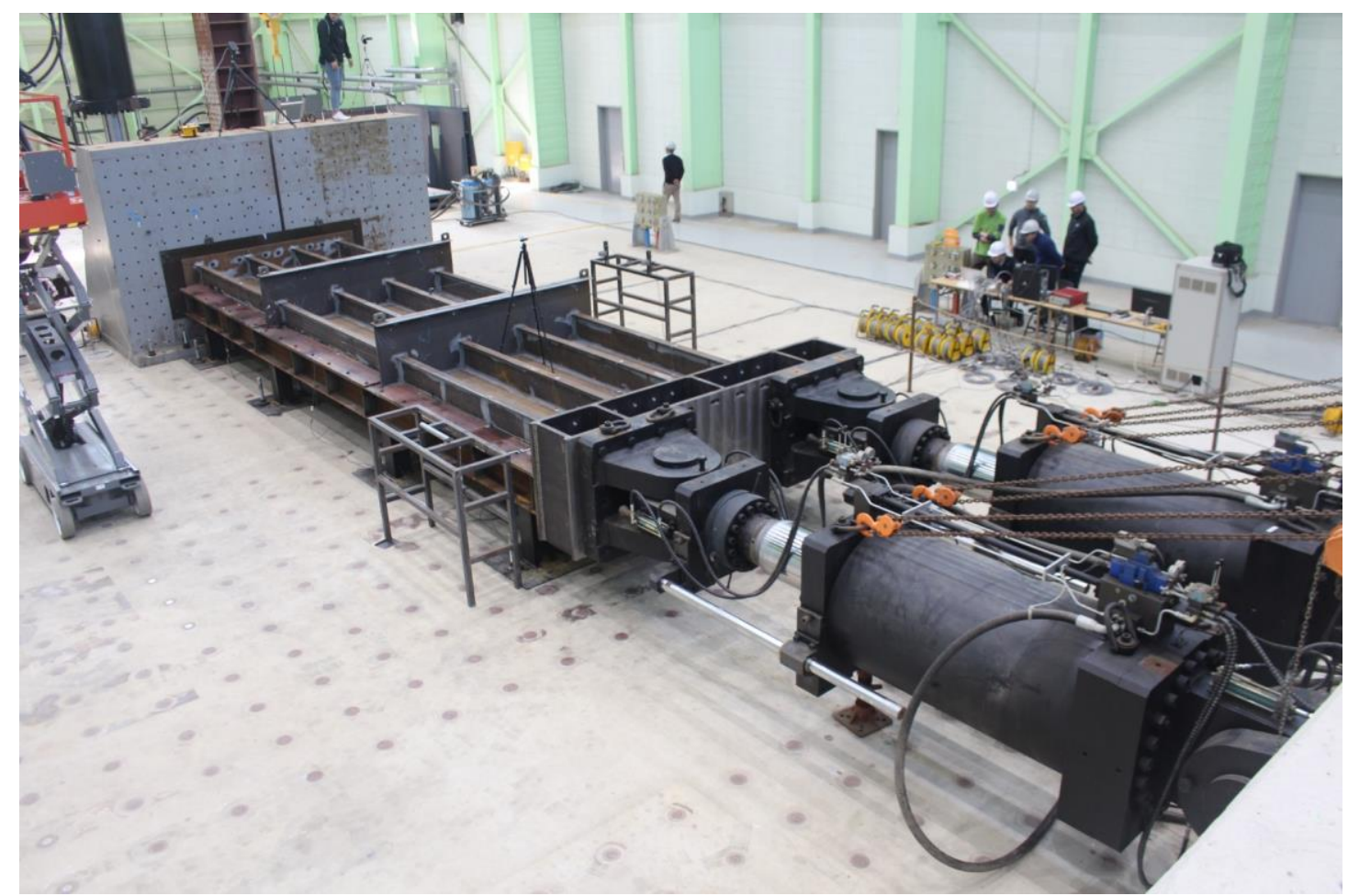

Figure 18. The test set-up at the test site of the ICASS/KOSORI in Hadong, South Korea.

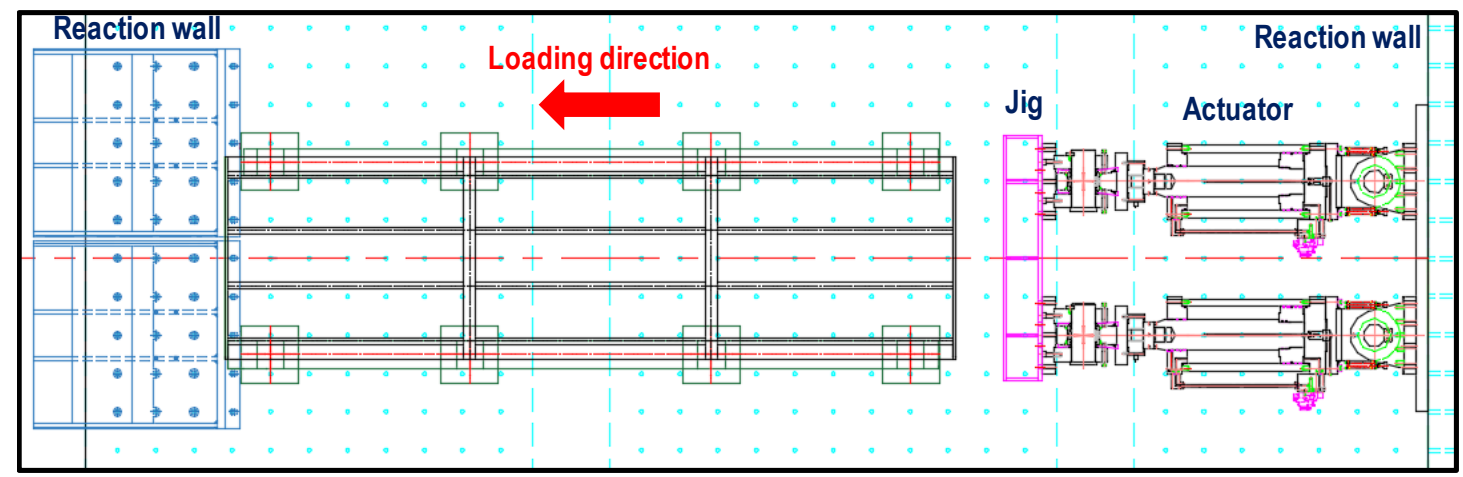

(a) Bird's eye view 


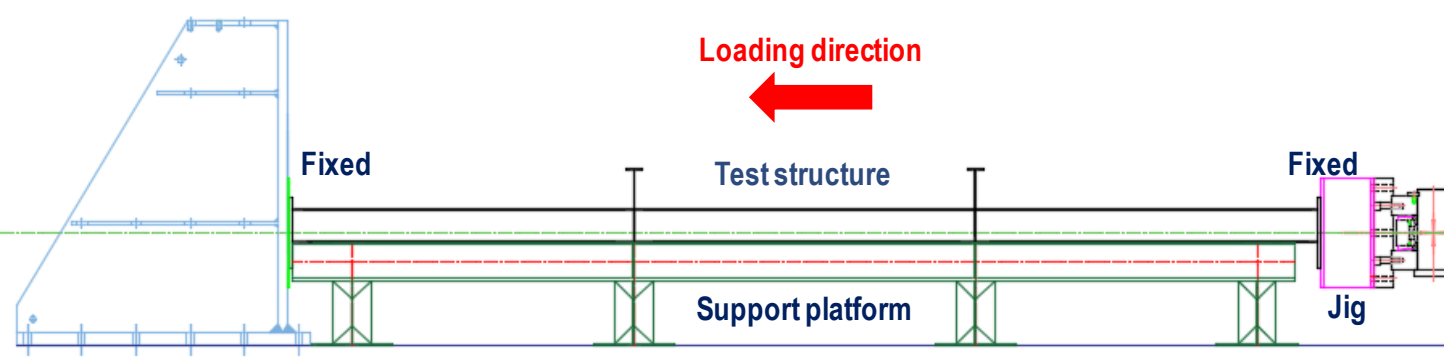

(b) Side view

Figure 19. A schematic of the test rig and the application of loading: (a) bird's eye view and (b) side view.

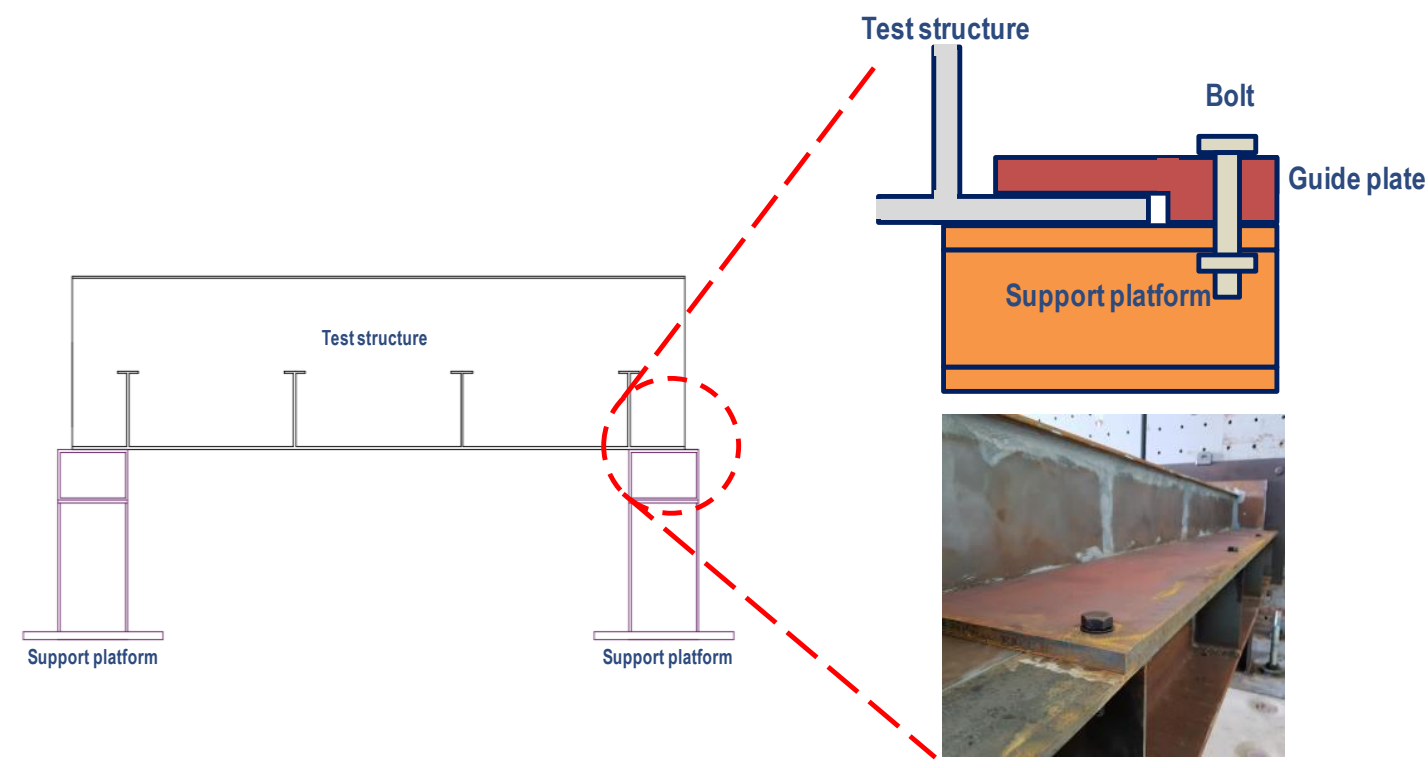

Figure 20. A schematic of the support system at unloaded edges.

\section{Acquisition of test data}

The test structure was equipped with many sensors in order to measure as much as possible from a test (see Figure 21). The axial displacement was measured at two locations (AC2 and AC3) using a dynamic data logger with a sampling frequency at every $0.002 \mathrm{~s}$. The axial compressive loads were measured by load cells placed on the head of each hydraulic actuator (AC2 and AC3). Thirteen LVDT (linear variable differential transformer) sensors were installed below the horizontally positioned test structure to measure the vertical deflection along the centreline of the plate panel (LV1 to LV13). Two wired LVDT sensors were installed on the flange of a longitudinal stiffener to measure the transverse (sideways) displacement of the longitudinal stiffener (LW1 and LW2). Figure 22 shows a picture of the LVDT sensors embodied in the test structure, which are wired to a personal computer. 


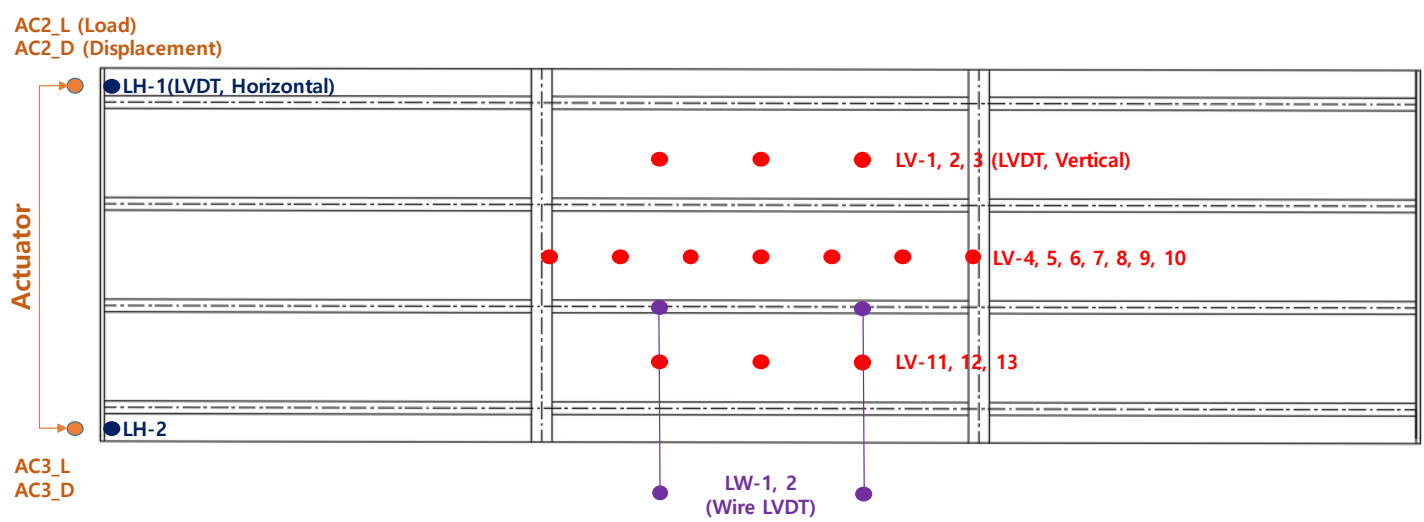

Figure 21. Monitoring points of loads and displacements on the test structure.

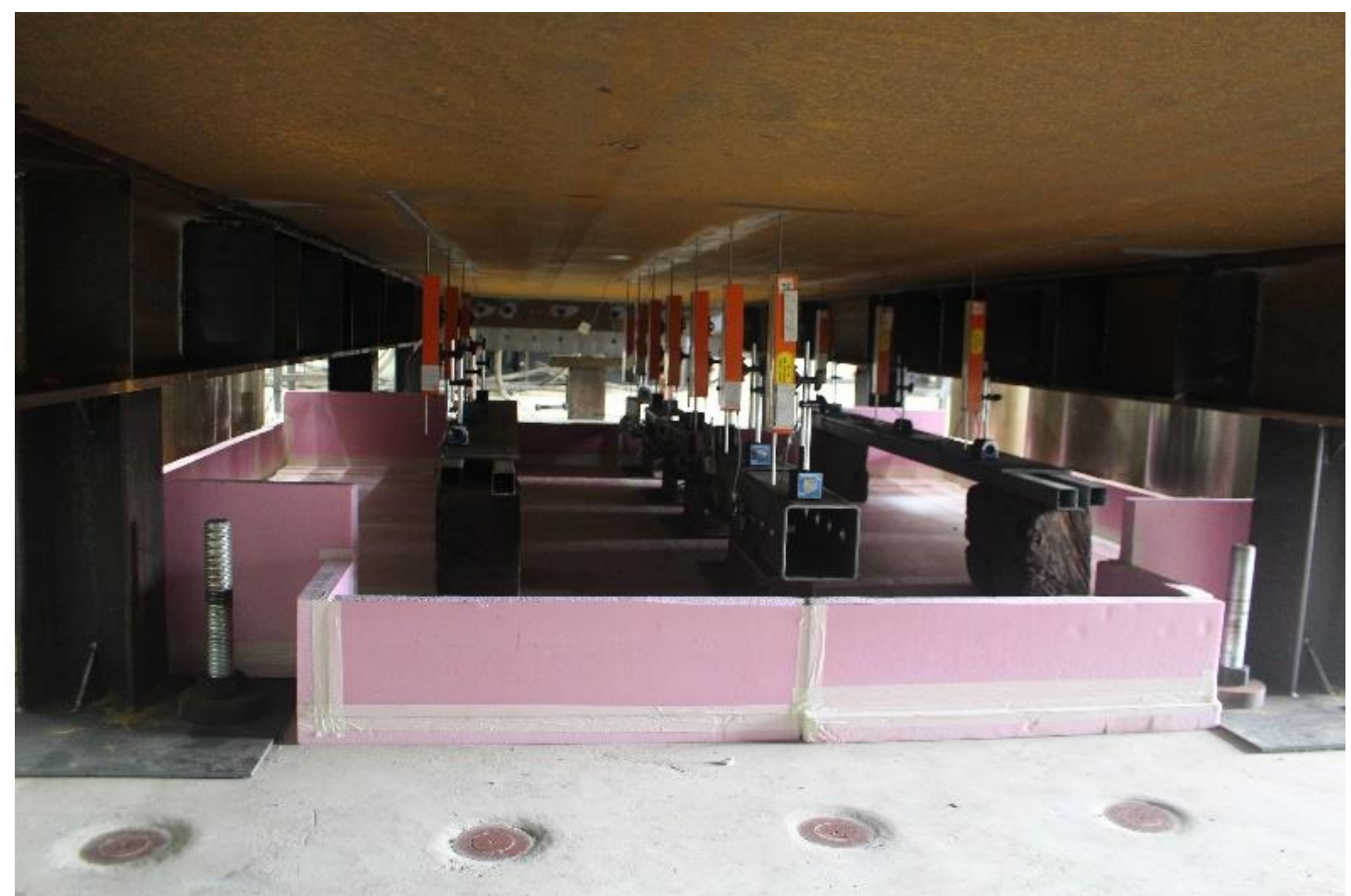

Figure 22. LVDT sensors embodied in the test structure for measuring displacements.

\section{Cooling for achieving cryogenic condition}

To attain the cryogenic condition in the test structure, liquefied nitrogen gases were used instead of LNG or liquefied hydrogen due to safety reasons. The boiling point of liquefied nitrogen gas is $-195.8^{\circ} \mathrm{C}$ which is lower than $-163^{\circ} \mathrm{C}$ of $\mathrm{LNG}$, and also nitrogen gas is stable, non-reactive and non-toxic. A risk analysis showed that the released nitrogen gas could potentially reduce the oxygen content in the atmosphere of the indoor space at the test site. Hence, the main door of the test building was opened and large electric fans were run to secure ventilation during the testing. Also, all the experimenters wore personal protective equipment to secure safety against liquefied nitrogen gas. 
The liquefied nitrogen gas was sprayed only into the central bay of plate panel, as shown in Figure 23, which is the target region to observe the brittle fracture failure and other potential collapse modes. Furthermore, a nozzle was designed to spray liquefied nitrogen gas by minimizing their vaporization during the cooling process as shown in Figure 24. The inside of the nozzle was covered by a strip of stainless steel which helped the nitrogen gas to flow out from the insulated hoses in liquid state.

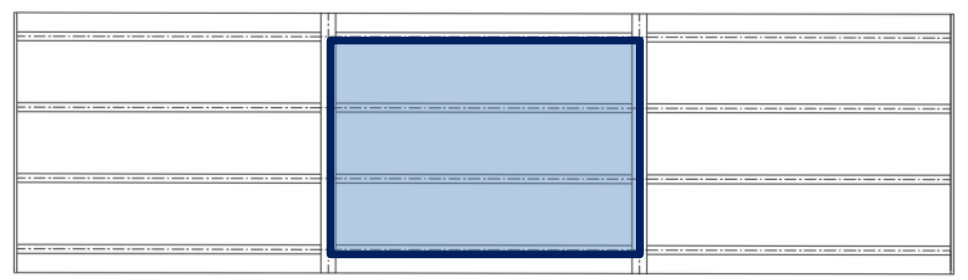

Figure 23. Target cooling region at the central bay of the test structure.
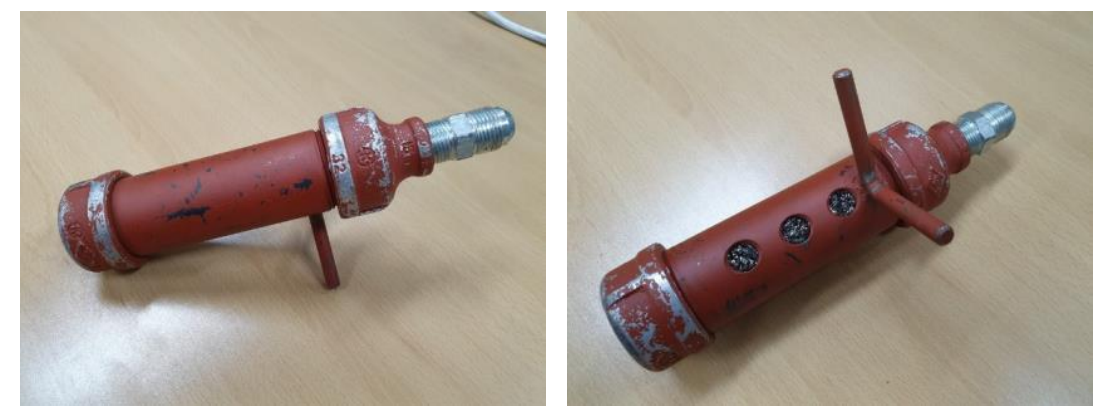

Figure 24. Specially designed nozzle to spray liquefied nitrogen gas into the central bay of the test structure.

To secure the success of the cooling process, a trial cooling test was carried out in advance using a physical model with $1 / 3 \mathrm{~m} \times 1 / 3 \mathrm{~m} \times 1 \mathrm{~m}$ in space as shown in Figure 25. The aims of this test were:

- to examine the performance of the nozzle,

- to estimate the required quantity of liquefied nitrogen gas for the large scale test structure,

- to estimate the required cooling time for the large scale test structure, and

- to inquire the safety.

The liquefied nitrogen gases were filled to half of the stiffener height of the test object. The steel temperature was measured by T-type thermocouples until all the filled liquefied nitrogen gas had evaporated. Figure 26 presents the change of steel temperature with time from the trial cooling test. Important insights in terms of the required quantity of liquefied nitrogen gas and the required cooling time for the large scale test structure could be learned from the trial test. Based on the results, it was decided that the commencement of load application by the hydraulic actuators should be made after all the liquefied nitrogen gas filled in the test structure had been 
evaporated so that the cold gas temperature was fully transferred into steel and stabilized during the testing.
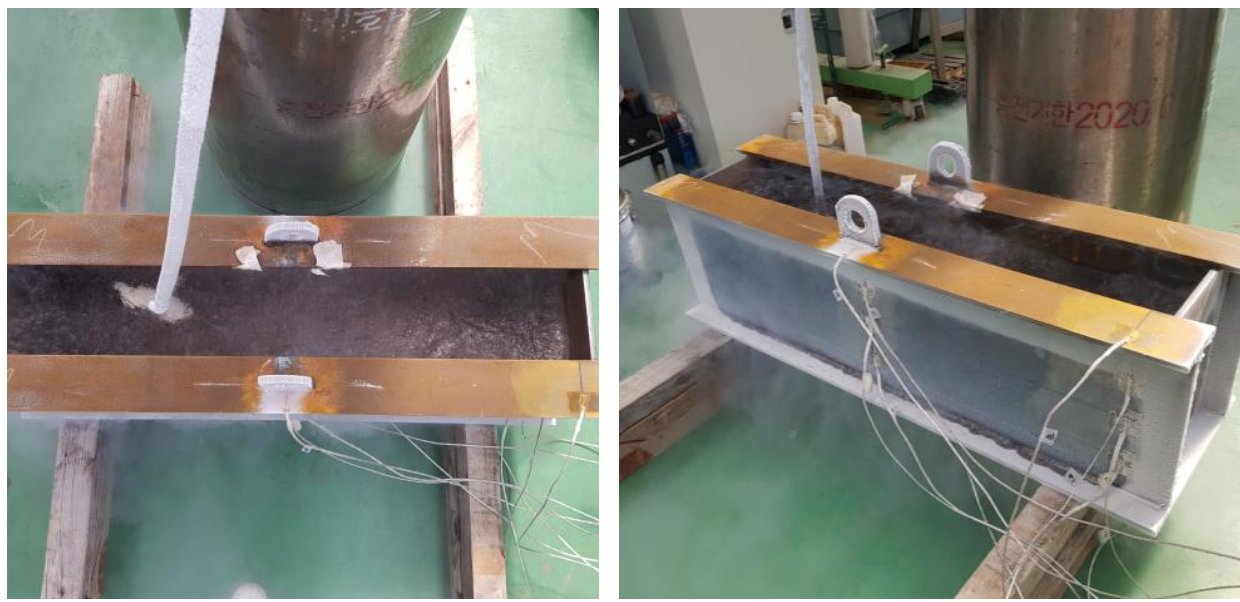

Figure 25. Photos from the test object used in the trial cooling test.
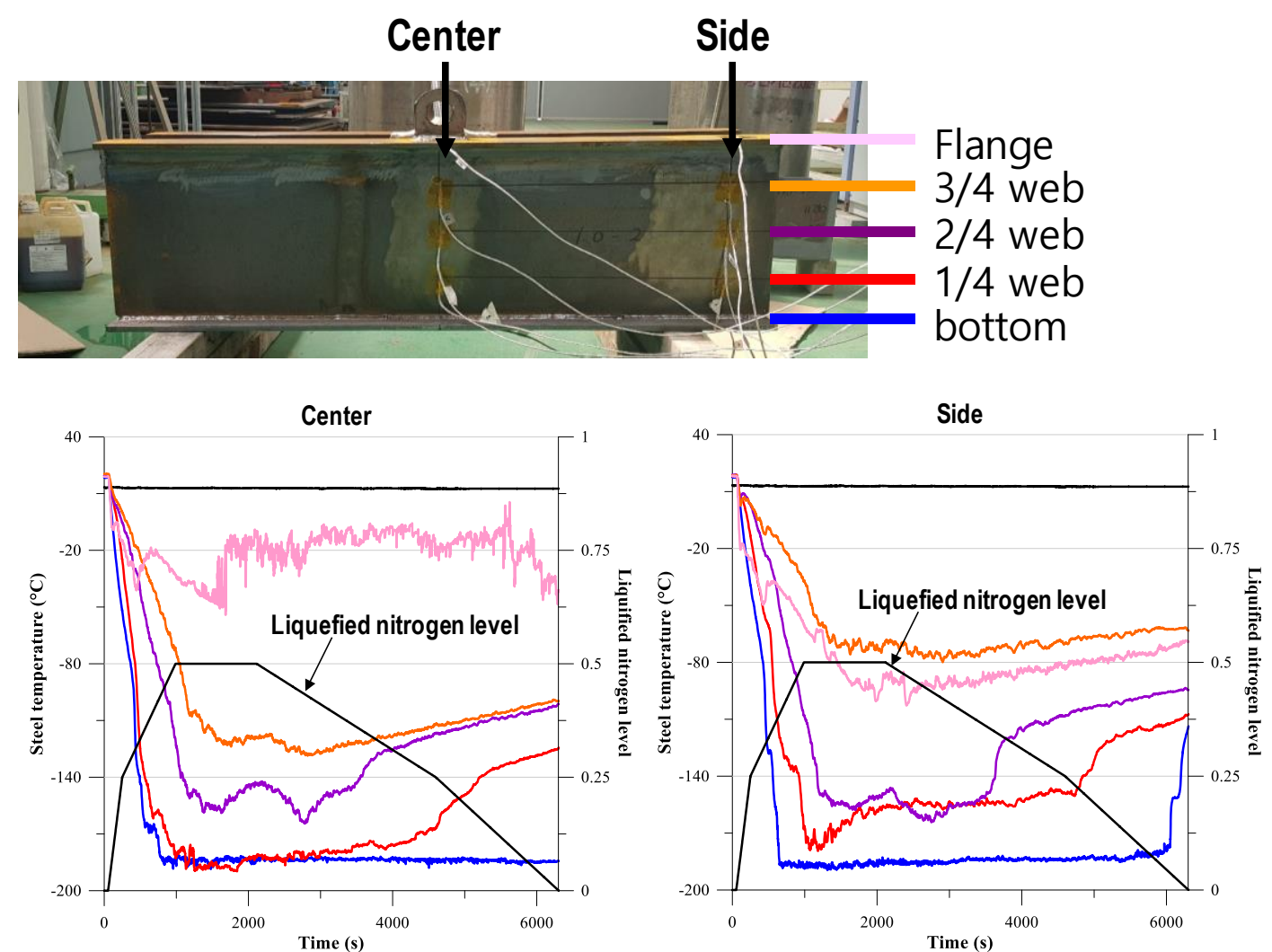

Figure 26. Change of steel temperature with time at various monitoring points in the test object, measured from the trial cooling test. 


\section{Test results and discussion}

\subsection{Steel temperature under cryogenic condition}

Similar to the trial cooling test structure, the central bay of the test structure was filled by liquefied nitrogen gas to half of its longitudinal stiffener height. Figure 27 shows the cooling process of the test structure where the top of the cooling region was covered by insulating sheets made of Styrofoam during the injection of the liquefied nitrogen gas. The application of the axial compressive loading by the hydraulic actuators started after all liquefied nitrogen gas was completely evaporated.

Figure 28 shows the change in steel temperature with time during the testing. It is confirmed from Figure 28 that the steel temperature remained almost constant during the entire test. The average steel temperature in the plate was about $-160^{\circ} \mathrm{C}$. In other parts of the structure, the steel temperature was slightly higher such as $-100^{\circ} \mathrm{C}$ in the upper part of the longitudinal stiffener web, $-125^{\circ} \mathrm{C}$ in the mid-part and $-150^{\circ} \mathrm{C}$ in the lower part. The average steel temperature in the stiffener flange was about $-80^{\circ} \mathrm{C}$. The non-uniformity in steel temperature over the structure is of course natural in reality during the non-uniform evaporation of released liquids. Also, it is considered that the cryogenic condition obtained in the test is reasonable because the temperatures of liquefied natural gases or hydrogen are $-163^{\circ} \mathrm{C}$ or $-253^{\circ} \mathrm{C}$, respectively.

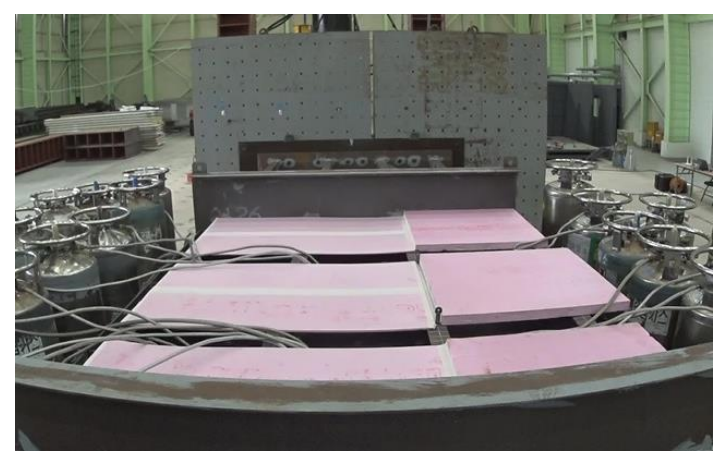

(a) Set-up for cooling process

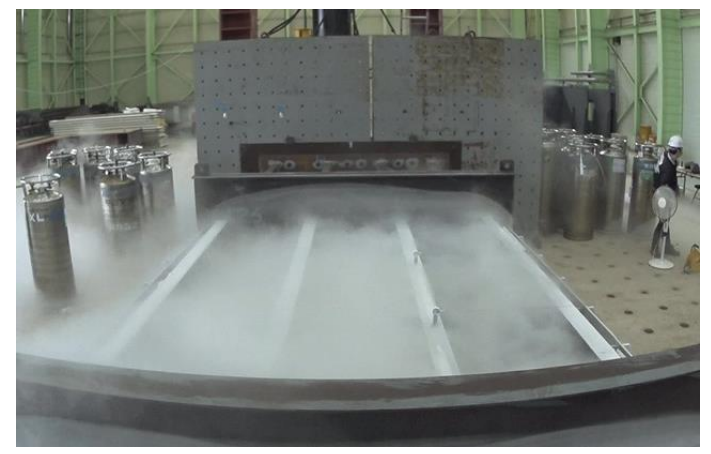

(c) Evaporation of liquefied nitrogen gas

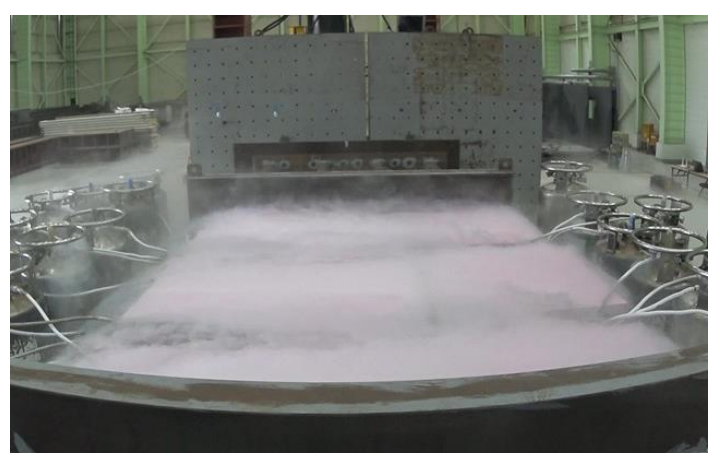

(b) Injection of liquefied nitrogen gas

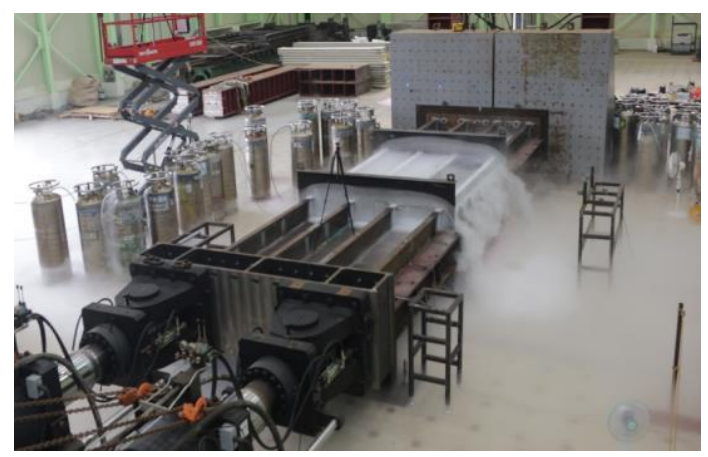

(d) Completion of the cooling process

Figure 27. Cooling process of the test structure. 

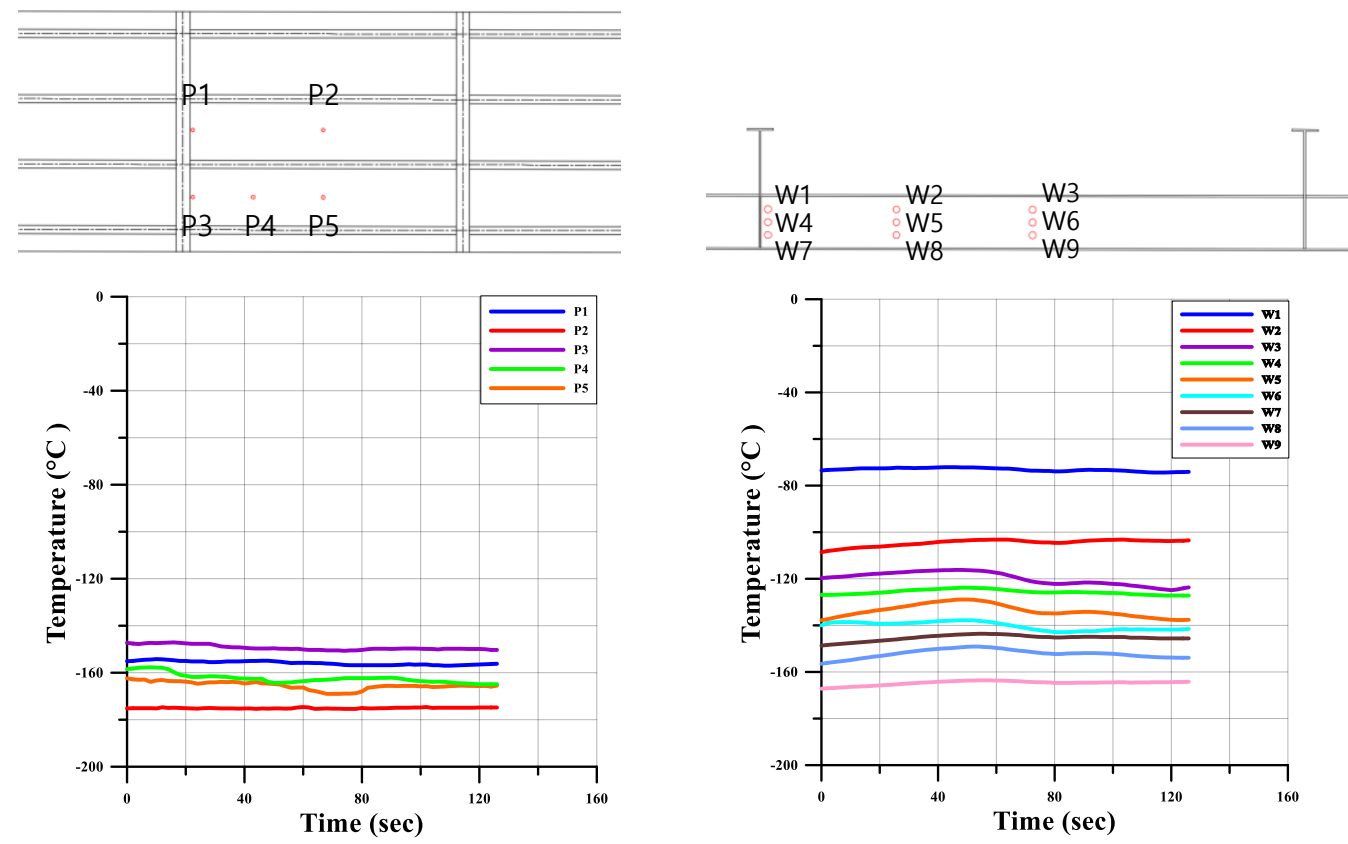

(a) In the plate

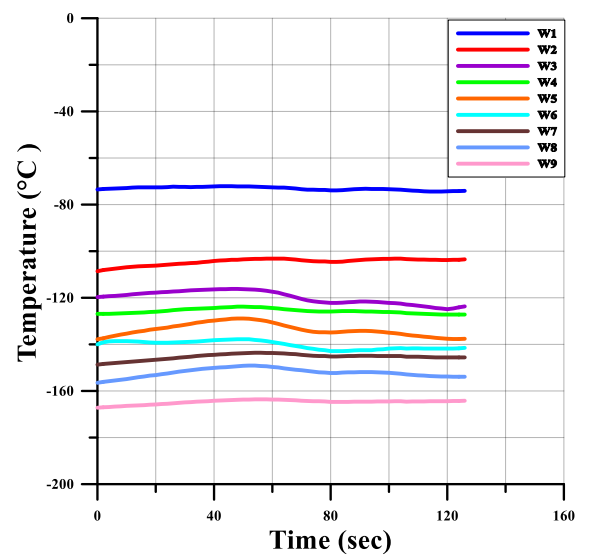

(b) In the longitudinal stiffener web
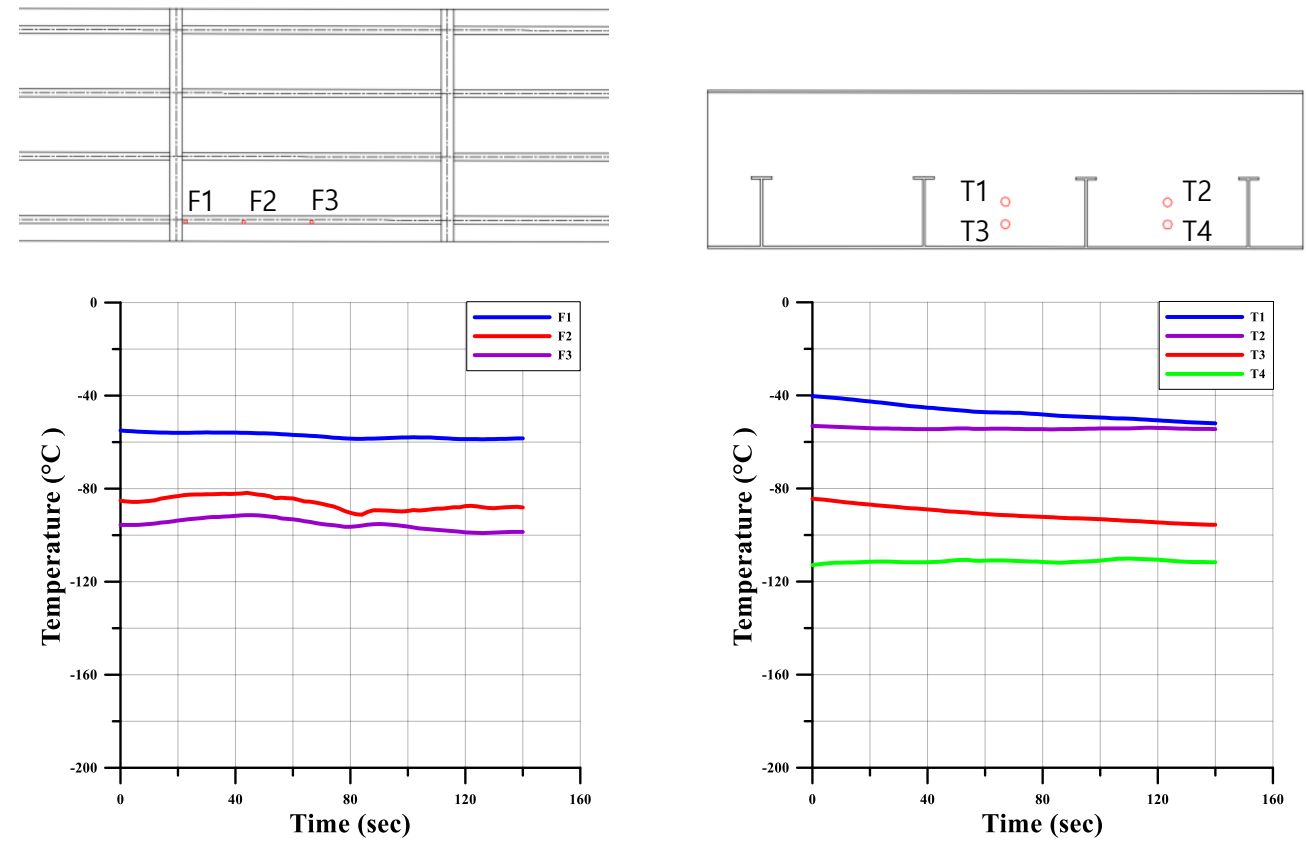

(c) In the longitudinal stiffener flange

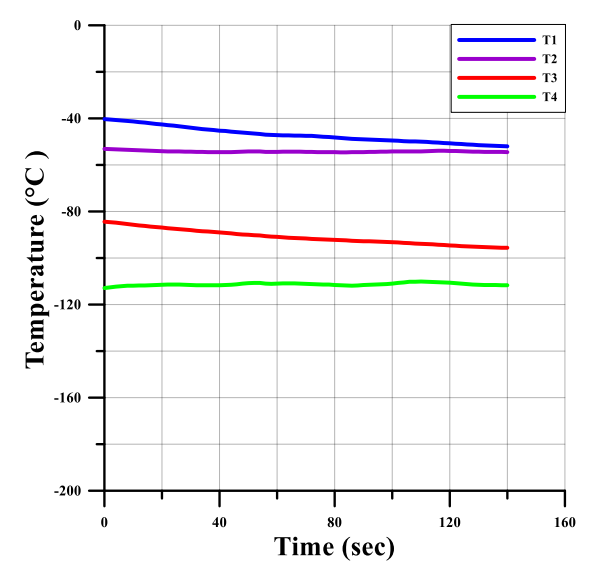

(d) In the transverse frame web

Figure 28. Change in steel temperature with time during the testing.

\subsection{Structural crashworthiness}

Figure 29 presents the axial compressive load versus the axial shortening curve from two similar test structures at room temperature and at cryogenic condition, respectively. The room temperature test was carried out with cyclic axial compressive loading and it is described in detail in a separate paper of Paik et al. (2020). The Appendix provides the test data in terms of the load-axial shortening relation at cryogenic condition, which can be used by other engineers for the purpose of comparison with their computational models. 
Figure 30 shows the photos after the testing was completed at cryogenic condition where brittle fracture triggered the ultimate limit states of the structure. The main portion of the plate and the longitudinal stiffeners was totally torn out by brittle fracture in a sudden event like an explosion. The cross-section of the plate was cut off sharply by brittle fracture as shown in Figure 31. No visible plastic deformations were observed and the crack propagation happened with big sound instantly while pieces of separated plating were flying.

Figures 32 and 33 compare the deformations of the plate and longitudinal stiffeners measured for the test structures at room temperature and cryogenic condition. It is seen that the deformations of the plate at cryogenic condition were very small, while a distinct buckling phenomenon with collapse mode $\mathrm{V}$ took place at room temperature (Paik et al. 2020). The failure modes of the test structure at cryogenic condition are totally different from those at room temperature, where the compressive brittle fracture in structural elements triggered the failure of the entire structure.

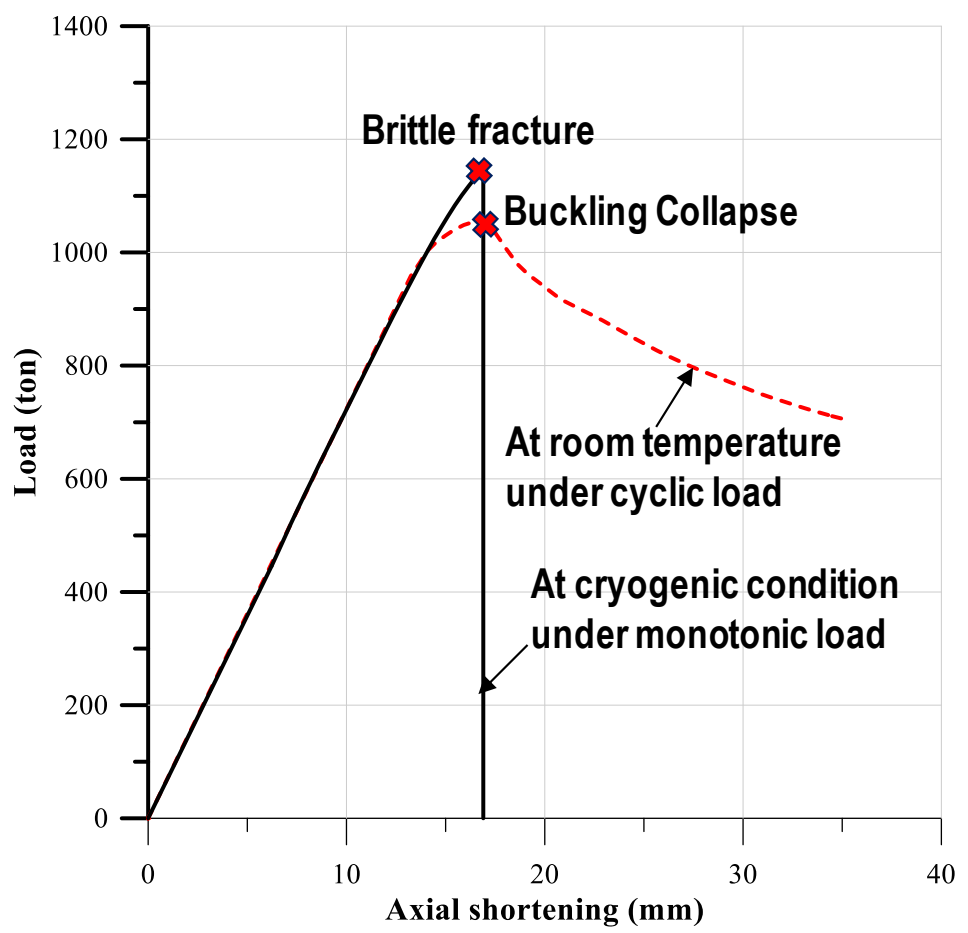

Figure 29. Axial compressive load-axial shortening curves of the test structures at room and cryogenic temperature. 

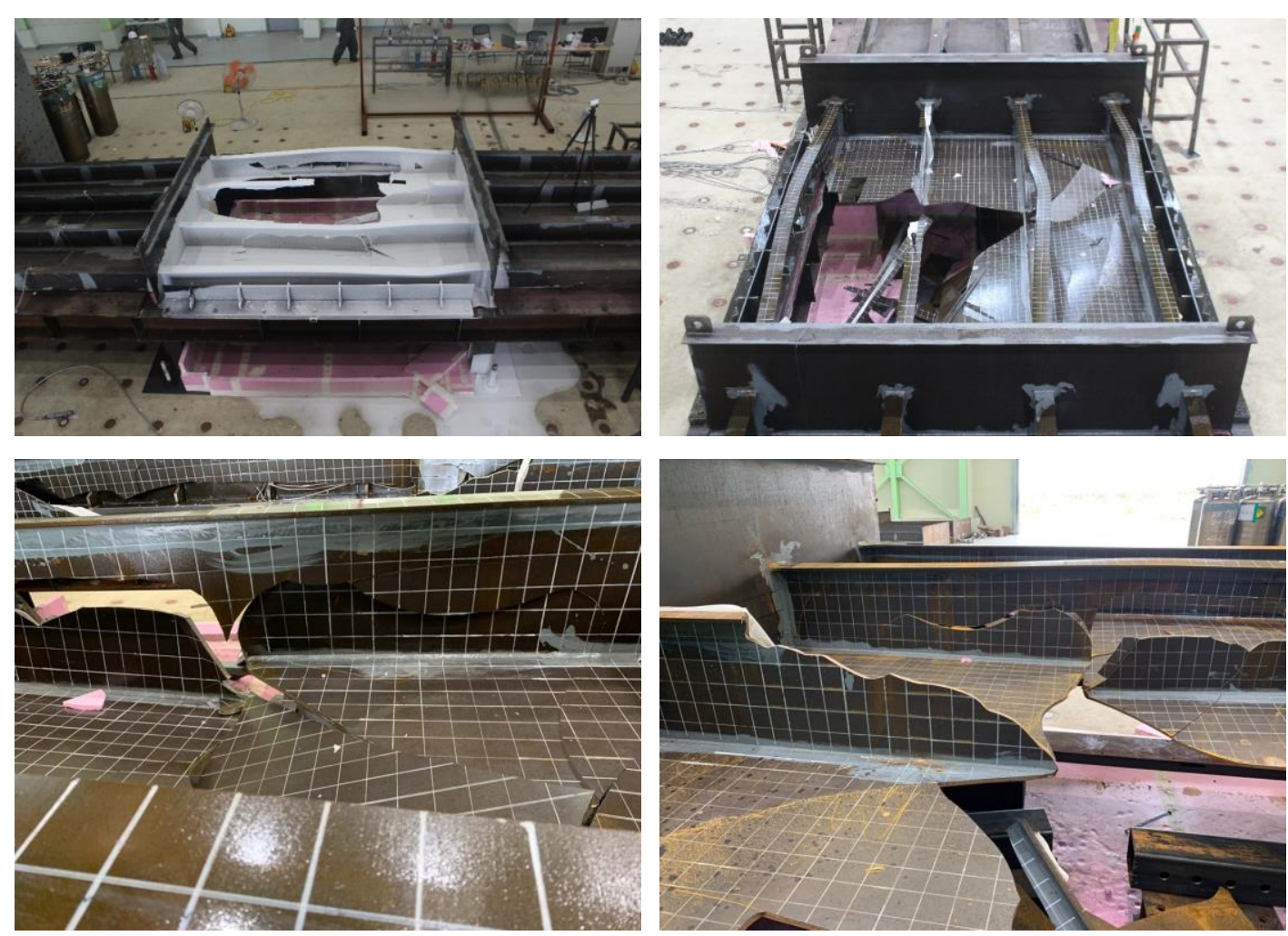

Figure 30. Brittle fracture of the test structure at cryogenic condition.
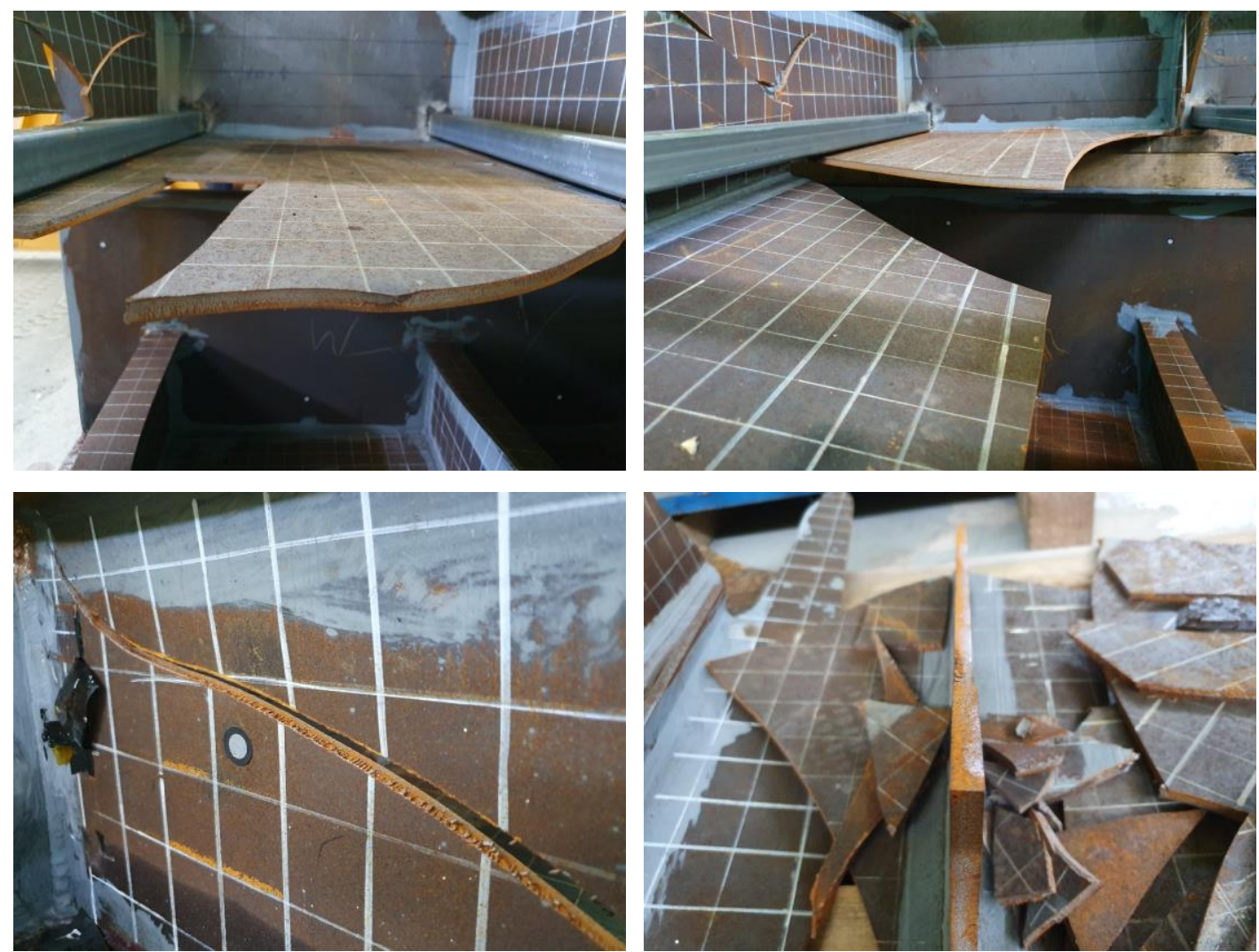

Figure 31. Sharp cross-sectional separation of plating due to brittle fracture. 

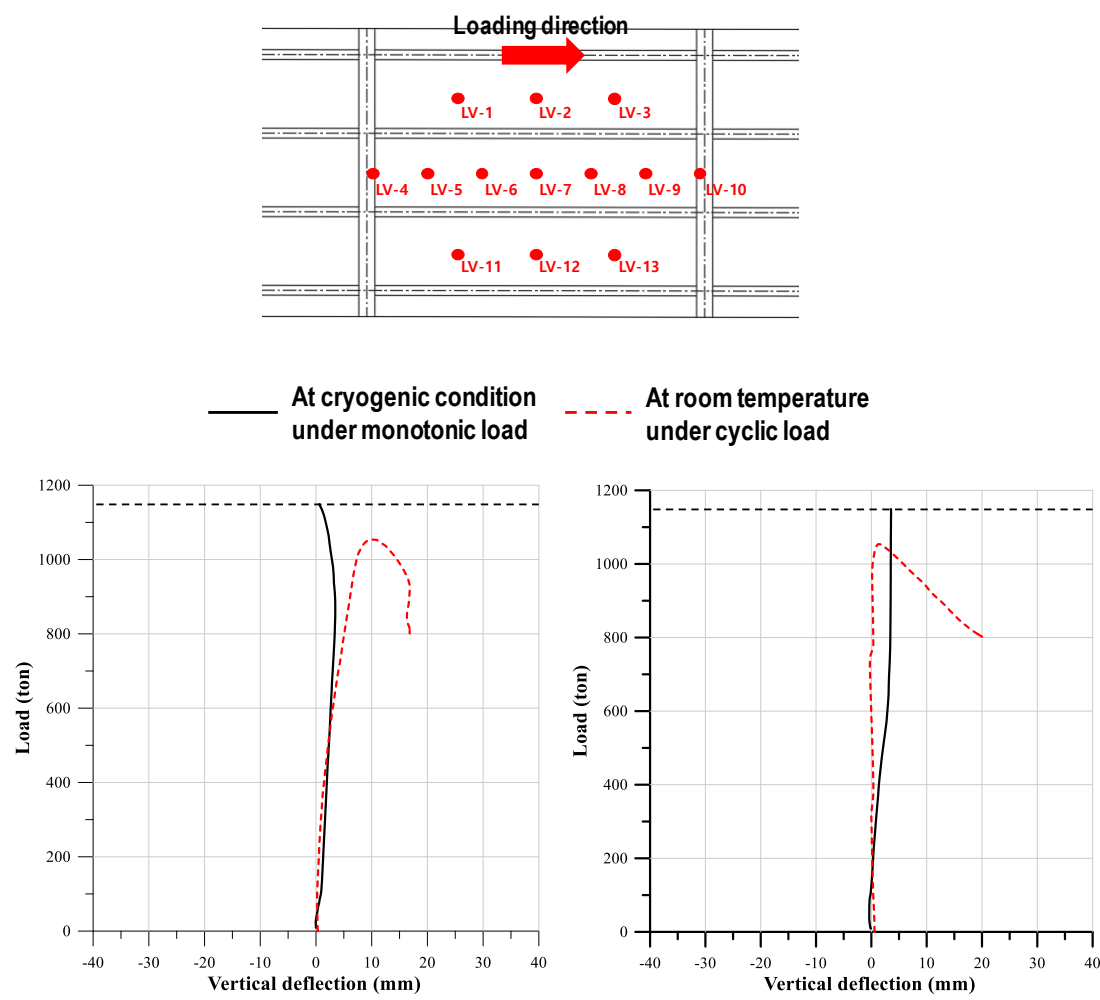

(a) LV-1

(b) LV-2
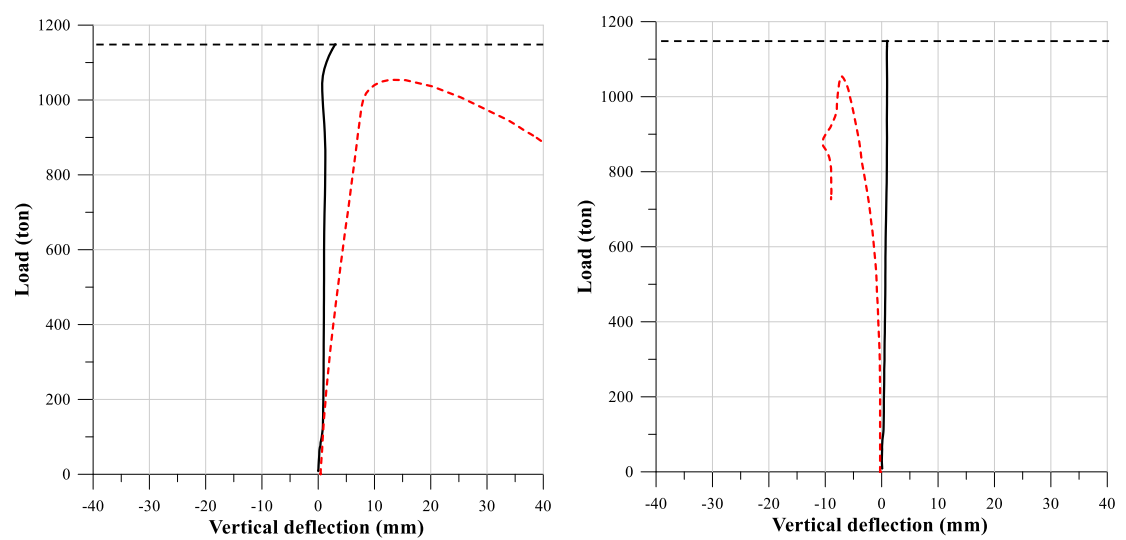

(c) LV-6

(d) LV-9
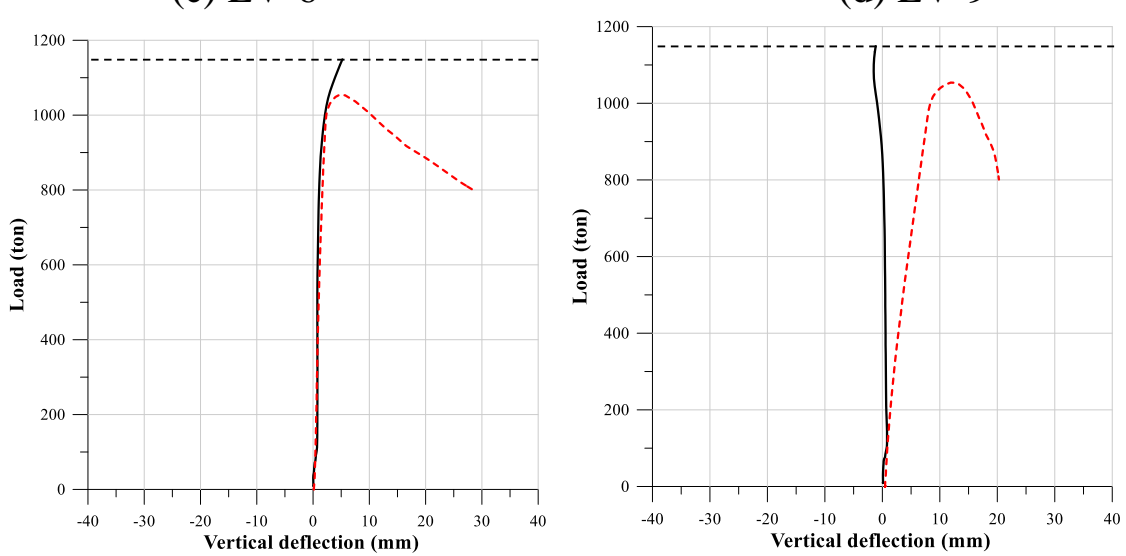

(e) LV-11

(f) $\mathrm{LV}-12$

Figure 32. Comparison of the deformations in the plate between room temperature (dashed line) and cryogenic condition (solid line). 


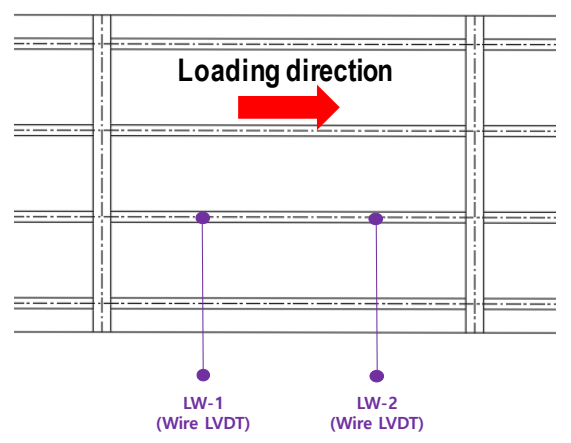

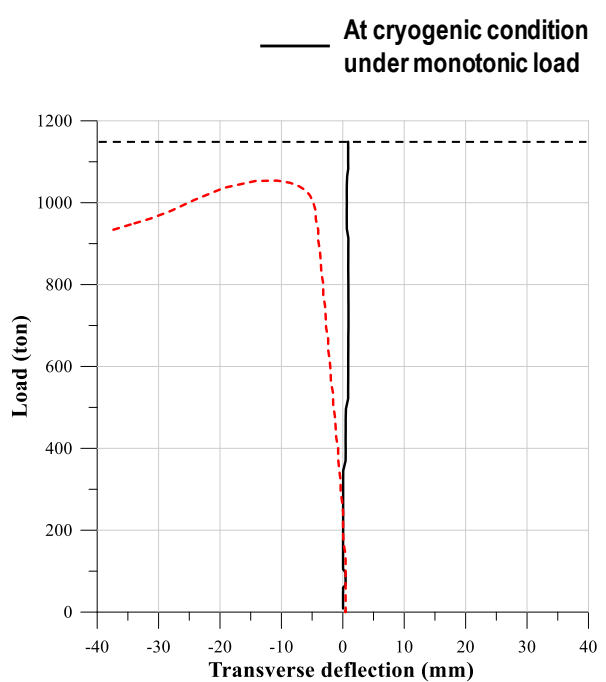

(a) LW-1

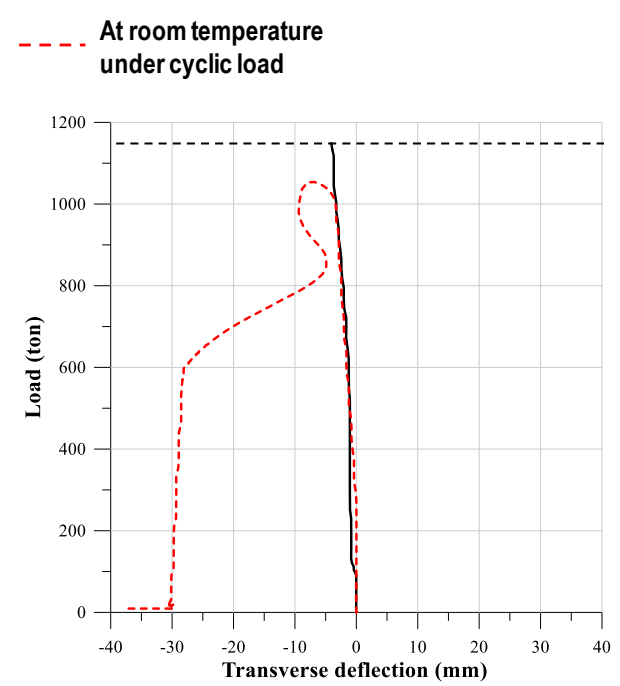

(b) LW-2

Figure 30. Comparison of the deformations in the longitudinal stiffeners between room temperature (dashed line) and cryogenic condition (solid line).

Table 6. Comparison of structural responses at room temperature versus cryogenic condition.

\begin{tabular}{|c|c|c|c|}
\hline Parameter & $\begin{array}{c}\text { At room } \\
\text { temperature (Paik } \\
\text { et al. 2020) }\end{array}$ & $\begin{array}{c}\text { At cryogenic } \\
\text { condition }\end{array}$ & Difference \\
\hline Stiffness (ton/mm) & 72.36 & 72.38 & $+0.03 \%$ \\
\hline $\begin{array}{c}\text { Ultimate strength } \\
\text { (ton) }\end{array}$ & 1054.04 & 1149.06 & $+9.01 \%$ \\
\hline $\begin{array}{c}\text { Axial shortening up } \\
\text { to collapse (mm) }\end{array}$ & 16.40 & 16.90 & $+3.05 \%$ \\
\hline $\begin{array}{c}\text { Strain energy up to } \\
\text { collapse (ton·mm) }\end{array}$ & 9506.43 & 10179.96 & $+7.08 \%$ \\
\hline Local buckling & Occurred & None & - \\
\hline Brittle fracture & None & Occurred & - \\
\hline
\end{tabular}

Table 6 summarizes the quantitative observations of the characteristics on the structural integrity until the ultimate limit states of the test structures were reached. 
While the structure at room temperature reached the ultimate strength by local buckling and plastic collapse (mode V), brittle fracture triggered the ultimate limit state of the structure at cryogenic condition without distinct buckling and plastic deformation. Also, the ultimate strength at cryogenic condition increased by $9.01 \%$ compared to the room temperature results, but the structural behaviour in the post-ultimate strength regime became extremely unstable at cryogenic condition as confirmed from Figure 29.

\section{Concluding remarks}

This study presented the design of a test structure and an experiment on the ultimate limit state of a full-scale physical model of a steel stiffened plate structure under axial compressive loads at cryogenic condition. It was motivated by the fact that the risk for unwanted release of liquefied natural gases or hydrogen has increased in modern ships associated with liquefied gas cargo transportation or alternative fuel for propulsion. Based on the study, the following conclusions can be drawn.

(1) The mechanical properties of a high tensile steel with grade AH32 used for fabricating the test structures were identified from tension and compression tests at low temperatures and cryogenic condition. At low temperatures, it is found that the yield strength of material in compression is much smaller than in tension, and this trend becomes more severe with decrease in temperature. It is obvious that the Bauschinger effect cannot be neglected at low temperatures, unlike at room temperature.

(2) The failure modes of steel plated structures under axial compressive loads at cryogenic condition are totally different from typical collapse modes at room temperature until and after the ultimate limit state is reached. Steel plated structures at room temperature reach the ultimate limit state by local buckling and plastic collapse, but the compressive brittle fracture in local structural elements is a primary trigger at cryogenic condition. No visible plastic deformations and local buckling took place until the ultimate strength was reached at cryogenic condition. This may be associated with the failure mechanism of ductile-to-brittle fracture transition at low temperatures.

(3) The ultimate strength of the structure at cryogenic condition is increased by some $9 \%$ compared to the reference test structure tested at room temperature, but the behaviour in the post-ultimate strength regime is extremely unstable at cryogenic condition as internal forces drop suddenly due to brittle fracture.

(4) At cryogenic condition, local members in the structure are sharply torn out by brittle fracture. This will lead to catastrophe in vessels involving liquefied natural gases or hydrogen as fuels or cargoes.

(5) The test database developed in the present study can be used to validate computational models for the structural crashworthiness analysis at cryogenic condition.

(6) Further studies are obviously recommended. At the material level, the failure mechanism and properties of ductile-to-brittle fracture transition at low (sub-zero) temperatures shall be characterized for structural steels. The 
Bauschinger effects for structural steels shall be characterized in association with low temperatures and strain rates (impact loading), among other factors. At the structure level, full-scale physical tests on the ultimate strength of steel stiffened plate structures at different low temperatures are encouraged to conduct. Advanced computational models for the structural crashworthiness analysis at low temperatures need to be developed.

\section{Acknowledgements}

This work was undertaken in the International Centre for Advanced Safety Studies, www.icass.center (the Korea Ship and Offshore Research Institute) at Pusan National University which has been a Lloyd's Register Foundation Research Centre of Excellence since 2008. Part of the work was supported by the Swedish Research Council by the project "Fundamental research on the ultimate compressive strength of ship stiffened plate structures at Arctic and cryogenic temperatures", contract no. 2018-06864.

\section{ORCID}

Jeom Kee Paik: http://orcid.org/0000-0003-2956-9359

Jonas W. Ringsberg: http://orcid.org/0000-0001-6950-1864

\section{References}

ALPS/ULSAP. 2019. A computer program for the ultimate limit state assessment of plates and stiffened panels. MAESTRO Marine LLC, Greenboro, MD, USA (www.maestromarine.com).

ASTM. 2015. E8/E8M: Standard test methods for tension testing of metallic materials. ASTM International, American Association State, West Conshohocken, PA, USA.

ASTM. 2018. E9: Standard test methods of compression testing of metallic materials at room temperature. ASTM International, American Association State, West Conshohocken, PA, USA.

ASTM. 2019. A131/A131M: Standard specification for structural steel for ship. ASTM International, American Association State, West Conshohocken, PA, USA.

Berejnoi C, Perez Ipiña JE. 2015. Analysisof size and temperature effects in the ductile to brittle transition region of ferritic steels. Engineering Fracture Mechanics, 148: 180-191.

Brockenbrough RL, Johnston BG. 1981. USS steel design manual. United States Steel Corporation, Pittsburgh, PA, USA.

Bruchhausen M, Holmstrom S, Lapetite JM, Ripplinger S. 2017. On the determination of the ductile to brittle transition temperature from small punch tests on grade 91 ferritic-martensitic steel. International Journal of Pressure Vessels and Piping, 155: 27-34.

Chen L, Liu W, Yu L, Cheng Y, Ren K, Sui H, Yi X, Duan H. 2020. Probabilistic and constitutive models for ductile-to-brittle transition in steels: A competition between 
cleavage and ductile fracture. Journal of the Mechanics and Physics of Solids, 135: 103809.

DNVGL. 2018. DNV GL rules for classification: Ships (RU-SHIP) - Part 2 Materials and welding. Høvik, Norway.

Dow RS. 1991.Testing and analysis of $1 / 3$ scale welded steel frigate model. Proceedings of the International Conference on Advances in Marine Structures, Dunfermline, Scotland, 749-773.

Hughes OF, Paik JK. 2013. Ship structural analysis and design. Alexandria, USA: The Society of Naval Architects and Marine Engineers.

Iijima K, Suzaki Y, Fujikubo M. 2015. Scaled model tests for the post-ultimate strength collapse behaviour of a ship's hull girder under whipping loads. Ships and Offshore Structures, 10(1): 31-38.

ISO. 2015. 6892-3: Metallic materials - Tensile testing at low temperature - Part 3: Method of test at low temperature. International Organization for Standardization.

Kaminskji AA, Galatenko GV. 1999. On the temperature dependence fracture toughness in the brittle-to-ductile transition region. International Applied Mechanics, 35(4): 398-404.

KSNA. 1983. Handbook for ship design. $4^{\text {th }}$ Edition, The Kansai Society of Naval Architects, Osaka, Japan (in Japanese).

Lee DH, Paik JK. 2020. Ultimate strength characteristics of as-built ultra-large containership hull structures under combined vertical bending and torsion. Ships and Offshore Structures, https://doi.org/10.1080/17445302.2020.1747829.

Li Y, Shterenlikht A, Ren X, He J, Zhang Z. 2019. CAFÉ based multi-scale modelling of ductile-to-brittle transition of steel with a temperature dependent effective surface energy. Materials Science \& Engineering A. 755: 220-230.

Majzoobi GH, Mahmoudi AH, Moradi S. 2016. Ductile to brittle failure transition of HSLA-100 steel at high strain rates and subsero temperatures. Engineering Fracture Mechanics, 158: 179-193.

Paik JK. 2018. Ultimate limit state analysis and design of plated structures, $2^{\text {nd }}$ Edition. Chichester, UK: John Wiley \& Sons.

Paik JK. 2019. Advanced structural safety studies: with extreme conditions and accidents. Germany: Springer.

Paik JK, Kim KJ, Lee JH, Jung BG, Kim SJ. 2017. Test database of the mechanical properties of mild, high-tensile and stainless steel and aluminium alloy associated with cold temperatures and strain rates. Ships and Offshore Structures, 12(S1): S230-S256.

Paik JK, Lee DH, Kim SJ, Thomas G, Ma M. 2019. A new method for determining the design values of wave-inducedhull girder loadsacting on ships. Ships and Offshore Structures, 14(S1): S63-S90.

Paik JK, Lee DH, Noh SH, Park DK, Ringsberg JW. 2020a. Full-scale collapse testing of a steel stiffened plate structure under cyclic axial-compressive loading. Structures, https://doi.org/10.1016/j.istruc.2020.05.026.

Paik JK, Ryu MG, He K, Lee DH, Lee SY, Park DK, Thomas G. 2020b. Full-scale testing to collapse of steel stiffened plate structures under lateral patch loading 
(part 1) - without passive fire protection. Ships and Offshore Structures, https://doi.org/10.1080/17445302.2020.1764705.

Paik JK, Ryu MG, He K, Lee DH, Lee SY, Park DK, Thomas G. 2020c. Full-scale testing to collapse of steel stiffened plate structures under lateral patch loading (part 2) - with passive fire protection. Ships and Offshore Structures, https://doi.org/10.1080/17445302.2020.1764706.

Park SI, Kim SK, Paik JK. 2020. Safety-zone layout design for a floating LNG-fueled power plant in bunkering process. Ocean Engineering, 196: 106774, https://doi.org/10.1016/j.oceaneng.2019.106774.

Petti JP, Lopez C, Figueroa V, Kalan RJ, Wellman G, Dempsey J, Villa D, Hightower M. 2013. LNG vessel cascading damage structural and thermal. Sandia National Laboratories, Albuquerque, NM, USA.

Smith CS. 1976. Compressive strength of welded steel ship grillages. Transactions of the Royal Institution of Naval Architects, 118: 325-359.

Tanaka Y, Ogawa H, Tatsumi A, Fujikubo M. 2015. Analysis method of ultimate hull girder strength under combined loads. Ships and Offshore Structures, 10(5): 587-598.

Yi MS, Lee DH, Lee HH, Paik JK. 2020a. Direct measurements and numerical predictions of welding-induced initial deformations in a steel stiffened plate structure. Thin-Walled Structures, https://doi.org/10.1016/j.tws.2020.106786.

Yi MS, Noh SH, Lee DH, Seo DH, Paik JK. 2020b. Direct measurements, numerical predictions and simple formula estimations of welding-induced residual stresses in a steel stiffened plate structure. Structures, https://doi.org/10.1016/j.istruc.2020.05.030.

Appendix. The axial compressive load versus axial shortening relation of the tested structure at cryogenic condition.

\begin{tabular}{|c|c|}
\hline Load (ton) & Axial shortening $(\mathrm{mm})$ \\
\hline 0 & 0 \\
\hline 6.22729 & 445.8552 \\
\hline 6.559157 & 471.3306 \\
\hline 6.886211 & 496.4437 \\
\hline 7.205992 & 521.4012 \\
\hline 7.543863 & 546.6507 \\
\hline 7.883696 & 571.6617 \\
\hline 8.231786 & 596.5578 \\
\hline 8.576585 & 621.8171 \\
\hline 8.924053 & 646.8626 \\
\hline 9.281178 & 671.8032 \\
\hline 9.632973 & 696.528 \\
\hline 9.97978 & 720.9272 \\
\hline 10.3269 & 745.4813 \\
\hline
\end{tabular}




\begin{tabular}{|c|c|}
\hline 10.67239 & 769.9489 \\
\hline 11.01878 & 794.4591 \\
\hline 11.36419 & 818.5305 \\
\hline 11.7081 & 842.3724 \\
\hline 12.04392 & 866.2569 \\
\hline 12.38783 & 889.9919 \\
\hline 12.73356 & 913.2371 \\
\hline 13.07352 & 936.0999 \\
\hline 13.41262 & 958.8043 \\
\hline 13.75126 & 981.0547 \\
\hline 14.09248 & 1002.931 \\
\hline 14.42924 & 1024.184 \\
\hline 14.77733 & 1044.529 \\
\hline 15.12145 & 1064.309 \\
\hline 15.46968 & 1083.261 \\
\hline 15.82186 & 1101.266 \\
\hline 16.17924 & 1118.019 \\
\hline 16.5432 & 1133.956 \\
\hline 16.90112 & 1149.061 \\
\hline 16.90184 & 0 \\
\hline
\end{tabular}

